\title{
Predicting the presuppositions of soft triggers
}

\author{
Márta Abrusán
}

Published online: 1 May 2012

(C) The Author(s) 2012. This article is published with open access at Springerlink.com

\begin{abstract}
The central idea behind this paper is that presuppositions of soft triggers arise from the way our attention structures the informational content of a sentence. Some aspects of the information conveyed are such that we pay attention to them by default, even in the absence of contextual information. On the other hand, contextual cues or conversational goals can divert attention to types of information that we would not pay attention to by default. Either way, whatever we do not pay attention to, be it by default, or in context, is what ends up presupposed by soft triggers. This paper attempts to predict what information in the sentence is likely to end up being the main point (i.e. what we pay attention to) and what information is independent from this, and therefore likely presupposed. It is proposed that this can be calculated by making reference to event times. The notion of aboutness used to calculate independence is based on that of Demolombe and Fariñas del Cerro (In: Holdobler S (ed) Intellectics and computational logic: papers in honor of Wolfgang Bibel, 2000).
\end{abstract}

Keywords Presuppositions · Attention - Soft triggers · Aboutness · Lexical semantics of verbs $\cdot$ Factivity

\section{Introduction}

Most studies on presuppositions are concerned with the projection problem, i.e. the question of how presuppositions of complex statements can be predicted from the presuppositions of their parts. The question of why presuppositions arise to begin with is a more rarely discussed issue, with much of the field being agnostic about the problem. This paper aims to address this question in connection with so-called soft presuppositional triggers.

M. Abrusán ( $\square)$

Lichtenberg Kolleg, Georg-August-Universität Göttingen, Göttingen, Germany

e-mail: abrusan@alum.mit.edu 
Besides the agnostic position, there are two main types of attitudes to the triggering problem. The first answer is that presuppositions are just an arbitrary special type of meaning specified by the lexicon, requiring their own set of rules for combining with other elements when embedded in larger contexts. According to the second view, suggested in passing by Stalnaker (1974) and also endorsed by Simons (2001), Abusch (2010), Schlenker (2010), presuppositions might arise via pragmatic means from assumptions about rules that rational interlocutors follow, just like conversational implicatures.

Neither of the above approaches are satisfactory: the first approach is nonexplanatory and posits an enormous amount of complexity in the semantic system. The second approach is theoretically attractive, however it is fair to say that to this date no satisfactory mechanism has been given that can derive based on rational rules of conversation why certain aspects of the meaning (and not others) are turned into presuppositions. Further, psycholinguistic studies such as Chemla and Bott (2011) that measured reaction times of speakers when computing presuppositions that arise with factive verbs have found that these phenomena show different patterns of processing than would be expected if they were computed similarly to implicatures.

But there is also an alternative angle of looking at presuppositions. According to this, rather than being a special aspect of the semantic meaning or conversational implicatures, presuppositions arise as a phenomenon of attention that modulates the process of understanding an utterance. This idea was already implicit in the wellknown observation that presuppositions expose a figure-background structuring of the information conveyed by the sentence, where the asserted part corresponds to the figure, or the main point of the sentence, and the presupposition corresponds to the background, i.e. what is taken for granted by the speakers (cf. Stalnaker 1974; Karttunen and Peters 1979; Wilson and Sperber 1979; Soames 1989; Chierchia and McConnell-Ginet 2000). Approximately the same idea has also been taken up-in various theoretical incarnations-in some more recent work as well (see Abbott 2000; Simons et al. 2010; Abrusán 2011).

This paper attempts to predict how presuppositions of soft triggers arise from general rules of attention, i.e. how our minds structure and process large amounts of information. In doing so, I am inspired by studies in cognitive psychology and computational vision (e.g. Goldstein 2009; Itti and Koch 2001; Navalpakkam and Itti 2005, etc.). These studies show that we unconsciously group information in a scene into what forms a constitutive aspect of it and what is backgrounded. The mechanisms of visual attention are widely believed to operate at two distinct levels: There is a default (bottom-up) process of attention, and a task-driven, context sensitive (top-down) mechanism for attention, where the latter has a role in modulating what is selected as the main aspect of the scene that we perceive. This paper starts from the hypothesis that understanding the information conveyed by linguistic means, and in particular the presuppositions of soft triggers follow from the same rules and mechanisms of cognition that were uncovered in vision research. According to this, language understanding is sensitive to both bottom-up (default) mechanisms, as well as top-down (task-driven) factors that influence attention: the former appear as the default grammatical constraints and tendencies of 
interpretation, and the latter as contextual influences, derived from the background context and the aims and goals of interlocutors.

The need for this dichotomy is shown most clearly by the behavior of so-called soft triggers. I assume that the class of soft triggers is the class of presuppositional verbs, more precisely, I take soft triggers to be the class of presuppositions that can be traced back to the presence of some verb in the sentence. ${ }^{1}$ The presuppositions of such triggers are fairly easily suspendable in context, as was pointed out by Karttunen (1971b), Stalnaker (1974), Gazdar (1979), van der Sandt (1992), Chierchia and McConnell-Ginet (2000), Simons (2001), Beaver (2004), Abbott (2006), Romoli (2011), among others. For example, as Beaver (2004) observes, (1b), but not (1a) suggests that the student has plagiarized his work:

(1) a. If the TA discovers that [your work is plagiarized $]_{\mathrm{F}}$, I will be [forced to notify the Dean $]_{F}$.

b. If the TA [discovers $]_{\mathrm{F}}$ that your work is plagiarized, I will be [forced to notify the Dean $]_{F}$.

I start from the assumption that that presuppositions are inferences that are not about the main point. In order to deal with facts such as (1), we need a two-tier framework for predicting the presuppositions of soft triggers. There is a grammatically defined main point (which roughly, is given by those entailments that are by nature about the event time of the matrix predicate of $S$ ), and a secondary, pragmatic main point, which can be derived by markers such as focus and evidential expressions (and possibly other factors as well). The grammatically and the contextually defined main point might be different: In these cases, sentences have two main points that are relevant for presupposition triggering: the default (grammatical) and a secondary (pragmatic) one. When this happens, entailments that are to be presupposed have to be independent from both the default and the contextually defined main point. This predicts, as we will see, that in the examples of presupposition suspension such as (1a) no presupposition is triggered to begin with. Thus we might view presuppositions of soft triggers as a result of how attention structures the informational content of a sentence: bottom-up processes derive the grammatically defined main point, while contextual (top-down) processes modulate what becomes the main point in a given context.

This paper follows Stalnaker (1974) and some of the above mentioned authors in assuming that presuppositions are also part of the entailed meaning: Presuppositions are simply entailments that are in some way distinguished. Thus I will not attempt to explain why expressions entail what they do, for example why knowledge entails belief. What is proposed is only that given that such an entailment exists, there is a way of telling whether or not it will also be presupposed. In this framework a presupposition triggering mechanism can be viewed as a function that takes as its input the bivalent meaning of a sentence $S$ together with a context $C$, and outputs one or more entailments of $\mathrm{S}$ (and in some cases contextual entailments of $\mathrm{S}$ ), those

\footnotetext{
1 This is a slight departure from what is often assumed, as sometimes emotive factives such as regret are classified among the hard triggers (Cf. e.g. Abbott 2006). See Sect. 5.1 for the reasons for this. Further, I will not discuss presuppositions of questions and focus, nor sortal presuppositions.
} 
which are also presupposed. ${ }^{2}$ This paper only looks at unembedded sentences. I assume that presuppositions of complex sentences are derived from the presuppositions of atomic sentences they contain, via a separate projection mechanism.

A word of disclaimer: While the present proposal seems to make correct predictions in a large enough number of cases, it is most likely not complete: in particular it is probable that further examples of top-down mechanisms that shift attention (and thus presuppositions) will be uncovered. We are only beginning to scratch the surface of this difficult topic.

\section{Previous proposals}

An intuition that has been around for quite some time now is that presuppositions are the part of the content of the sentence that is in some sense "not the main point" of an utterance. E.g. Karttunen and Peters $(1979$, p. 1) define the presupposition of sentences as "propositions which the sentences are not primarily about but which have to be established prior to an utterance of the sentences in order for communication to go smoothly" (emphasis mine). Going one step further, Stalnaker (1974) suggested that some presuppositions are indeed generated precisely in order to make sure that an utterance does not make a heterogeneous contribution to the context, i.e. to allow speakers to know what the main point of the utterance was.

It is clear that "x knows that P" entails that P. It is also clear that in most cases when anyone asserts or denies that $\mathrm{x}$ knows that $\mathrm{P}$, he presupposes that $\mathrm{P}$. Can this latter fact be explained without building it into the semantics of the word? I think it can. Suppose a speaker were to assert that $\mathrm{x}$ knows that $\mathrm{P}$ in a context where the truth of $\mathrm{P}$ is in doubt or dispute. He would be saying in one breath something that could be challenged in two different ways. He would be leaving unclear whether his main point was to make a claim about the truth of $\mathrm{P}$, or to make a claim about the epistemic situation of $\mathrm{x}$ (the knower), and thus leaving unclear what direction he intended or expected the conversation to take. Thus, given what "x knows that P" means, and given that people normally want to communicate in an orderly way, and normally have some purpose in mind, it would be unreasonable to assert that $\mathrm{x}$ knows that $\mathrm{P}$ in such a context. (Italics mine)

So Stalnaker suggests that presuppositions are generated in order to avoid uncertainty as to what the main point of a speaker's contribution to the context is. ${ }^{3}$ But

\footnotetext{
2 Another option would be a view of presuppositions under which they are not part of the entailed meaning. In this case the triggering function would take as its input the 'total' meaning of $S$ (call it $\mathrm{TM}(\mathrm{S})$ ), i.e. the meaning we get by lumping together truth conditional and presupposed content, and output one or more entailment(s) of $\mathrm{TM}(\mathrm{S})$ as the presupposition. In this paper I use the Stalnakerian view and assume that presuppositions are also entailed, but it should be borne in mind that the present proposal is also compatible with a view of presuppositions where these are not entailed. Cf. Schlenker (2010) for a more detailed discussion of how these two views compare from a perspective of a triggering theory.

${ }^{3}$ Cf. also Abbott (2000) for a related idea. Abbott claims further that "[t]ypically, the asserted proposition in an utterance will correspond to the main clause of the uttered sentence", but does not offer further clarifications on this point.
} 
Stalnaker's remark does not make a prediction as to which part of the assertion should become the main point, and which should be presupposed (cf. Abusch 2010; Schlenker 2008, 2010 for more discussion.)

\subsection{Wilson and Sperber (1979)}

Wilson and Sperber's (1979) paper is the first proposal that attempts to explain why certain entailments of sentences exhibit the special properties of presuppositions. ${ }^{4}$ Instead of assuming, as usual, that semantic entailments of a sentence are an unordered set of propositions, they argue that this set is ordered by certain syntactic and intonational factors. On the basis of this internal structure of entailments, they set out to distinguish entailments that are focalized from those which are peripheral, and within the first group, distinguish those which are in the foreground of attention from those which are in the background. These linguistically determined distinctions can then be used to predict the presuppositional behavior of utterances.

Let's illustrate this with an example. The entailment of $S$ that we get by substituting the focused expression in $\mathrm{S}$ by an existentially quantified variable is its first background entailment. First background entailments act as presuppositions. In the case of (2a), where by assumption the complement of the attitude verb is focused, the first background entailment is $(2 b)$ :

(2) a. Susan knows [that it is raining $]_{F}$

b. Susan knows something

c. It is raining

An entailment that neither entails nor is entailed by the first background entailment is 'not involved in normal interpretation' (for our purposes: is presupposed). (2c) is such an entailment and therefore it will act as a presupposition, at least in contexts where the complement of the verb know is focused.

The proposal seems to make correct predictions for the presuppositions of focus (if that is indeed what they are, cf. Geurts and van der Sandt (2004) and replies to it in the same issue) and clefts. Wilson and Sperber also attempt to capture the discourse sensitivity of presuppositions. Such effects have been recently discussed in Beaver (2004) and Kadmon (2001). Unfortunately, it does not capture these correctly and it makes further incorrect predictions for a wide range of facts. First, one might wonder what happens if the focused constituent in (2) was the matrix subject? In this case the first background entailment would be that someone knows that it is raining. This entailment neither entails nor is entailed by the entailment that Susan believes that it is raining, which therefore should be presupposed, contrary to fact. Second, consider (3):

\footnotetext{
4 Technically, they deny the existence of presuppositions as separate category. What this means is that they deny the existence of conventionally postulated presuppositions. If presuppositions are the type of entities that can be predicted based on the overall meaning of a sentence, the difference between sayingas they do-that certain entailments which show the typical projective behavior of presuppositions can be distinguished as opposed to saying that precisely these entailments should be called presuppositions becomes immaterial.
} 


\section{(3) a. John killed $[\text { Bill }]_{\mathrm{F}}$ \\ b. John killed someone \\ c. Bill is dead}

The first background entailment of (3a) is (3b). This is independent from the entailment $(3 \mathrm{c})$, which should therefore be presupposed, contrary to fact. These problems are not unique to the particular examples mentioned above: a similar problem will arise with any attitude verb whose subject is focused, and any transitive verb whose object is focused. Thus it seems that Wilson and Sperber's (1979) theory does not succeed in making correct predictions.

\subsection{Simons (2001)}

The idea that a conversational explanation can be given as to why certain items stand with a presupposition was revived recently by Simons (2001). Thus rather than a semantic mechanism, Simons (2001) attempts a purely pragmatic mechanism of presupposition triggering, treading along the path envisaged by Stalnaker (1974). ${ }^{5}$ Her idea in a nutshell is as follows. By uttering a sentence $S$ a speaker raises the question $\mathrm{Q}$ if $\mathrm{S}$ can be interpreted as addressing the question $\mathrm{Q}$. Thus uttering an atomic sentence with content $p$ counts as raising the question $Q=$ Whether $p$ ?, and uttering a sentence with content $\neg p$ counts as raising the question $Q=$ Whether $p$ ? as well, and so does an utterance of a sentence with the content if $p$, then ..., and so on for other operators over which presuppositions project. ${ }^{6}$ Given this, she defines the triggering mechanism as follows:

(4) If a speaker A raises the question Whether $p$ ? by uttering $\mathrm{S}$, and $\mathrm{p}$ asymmetrically entails ${ }^{7}$ some proposition $\mathrm{q}$, then $\mathrm{A}$ indicates that she believes $\mathrm{q}$ to be true.

Let's look at an example. A speaker who utters (5a) raises the question in (5b), and indicates that she believes the proposition in (5d)—which is asymmetrically entailed by $(5 \mathrm{c})$ - to be true:

(5) a. $\mathrm{S}=$ John knows it is raining

b. $\quad \mathrm{Q}=$ Whether $\mathrm{p}$ ? = Whether John knows it is raining

c. $\quad \mathrm{p}=$ John knows it is raining

d. $\quad \mathrm{q}=$ It is raining

Since the sentence John does not know that it is raining would raise the same question, namely (5b), it would be predicted to trigger the same presupposition, and so on for other contexts.

\footnotetext{
5 The idea that at least some presuppositions should be conversationally triggered was also embraced by Chierchia and McConnell-Ginet (2000) and Kadmon (2001) and Schlenker (2010). Neither of these discussions offer a way to derive these presuppositions.

6 The idea of presuppositions raising question alternatives was also used in Chemla (2009) to predict presupposition projection.

7 A proposition $\mathrm{p}$ asymmetrically entails $\mathrm{q}$ if $\mathrm{p}$ entails $\mathrm{q}$, but $\mathrm{q}$ does not entail $\mathrm{p}$.
} 
As Simons (2001) herself points out, the proposal as it stands strongly overgenerates (cf. also discussion Abusch 2010). E.g. in connection with the example in (5), the proposal predicts that it should also presuppose that John believes that it is raining, and indeed any proposition that $S$ asymmetrically entails. This is certainly incorrect. It also predicts (6) to presuppose (6d), contrary to fact.

(6) John killed Bill

a. $\quad \mathrm{S}=$ John killed Bill

b. $\quad \mathrm{Q}=$ Whether $\mathrm{p} ?=$ Whether John killed Bill

c. $\mathrm{p}=$ John killed Bill

d. $\mathrm{q}=$ Bill is dead.

Further, from the fact that every asymmetrically entailed proposition is presupposed, it follows that every sentence is predicted to presuppose itself. ${ }^{8}$ This is because any sentence $S$ asymmetrically entails both $S \vee Q$ and $S \vee \neg Q$, for any proposition $\mathrm{Q}$. Therefore, $\mathrm{S}$ is predicted to presuppose both of these disjunctive propositions, and the intersection of the two is $\mathrm{S}$ itself.

Because of these grave problems, Simons suggests that the triggering principle should be refined in such a way that only those entailments of S should end up being presupposed that in some sense count as a precondition for the truth of $\mathrm{S}$. While the intuition is suggestive, the whole task of a triggering theory is to provide a definition for what it means for a proposition to be a precondition in this sense. Unfortunately Simons (2001) does not provide such a definition, and thus it is fair to say that the puzzle has not been solved by this paper.

\subsection{Abusch $(2002,2010)$}

Abusch's paper offers a prediction for a subset of presupposition triggers, which she identifies as soft triggers, including questions, focus and certain verbal triggers. These have a representation involving alternatives. It is standardly assumed that questions and focus introduce sets of alternative propositions which are derived by replacing the focused/questioned element by a contextually salient object of a suitable type. (Rooth 1992 wrt. focus, Hamblin 1973 and Karttunen 1977 wrt. questions.)

(7) a. Who came?

b. [Bill $]_{\mathrm{F}}$ came

c. The alternative set for both: $\mathrm{ALT}=\{$ that Bill came, that Mary came, $\ldots\}$

Abusch proposes that sets of alternatives trigger the default presuppositional constraint according to which the proposition formed as the disjunction of the set is true. This amounts to the claim that some alternative in the set is true, which is what gives rise to the (defeasible) existential presupposition triggered by focus and questions.

\footnotetext{
${ }_{8}$ This was pointed out to me by Emmanuel Chemla (p.c.)
} 
Abusch then goes on to extend the same idea to certain verbal presuppositional triggers. For these cases she stipulates that their lexical representation contains a set of alternatives. As before, the presupposition arises from the constraint that the disjunction of the alternatives is true. For example, the verbs know and stop trigger the following alternatives:

(8) a. know triggers the alternatives ALT $=\{$ know, be unaware $\}$

b. $\quad$ stop triggers the alternatives $\mathrm{ALT}=\{$ stop, continue $\}$

If a sentence $S$ that contains any of these triggers is uttered, the alternative propositions that we get by replacing the trigger by its lexical alternative are activated. Given the default presuppositional constraint, we then pragmatically presuppose that the disjunction of these alternative propositions is true:

(9) a. John knows that it is raining or John is unaware that it is raining

b. John stopped smoking or John continued to smoke

Since the disjunction still entails that it is raining (in the case of (9a)) or that John used to smoke (in the case of (9b)), the correct presupposition is predicted.

Abusch's account is convincing in the case of focus and questions, but somewhat more dubious when it comes to verbal triggers (cf. also discussion in Schlenker 2010). The problem is that while for focus and questions the alternative sets were derived simply by compositional semantics and pragmatics and were independently motivated, in the case of verbal triggers it needs to be lexically stipulated for each trigger what their alternative is. Since alternatives uniquely define what the presupposition is, it is not less of a stipulation to postulate lexical alternatives for verbal triggers than to simply postulate what their presupposition should be. There is no reason for example why the lexical alternative of know could not be believe, and in this case Abusch's system would predict that "x knows that $\mathrm{p}$ " should presuppose that " $\mathrm{x}$ believes that $\mathrm{p}$ ". There is also no principle from which it would follow that the verb kill should not trigger an alternative, and even less that this alternative could not be find dead, in which case the death of the object argument should be presupposed, incorrectly. Thus while Abusch makes correct predictions for the cases she discusses, what is missing from her proposal is a principled reason for where exactly the identity of the alternatives comes from, and thus her treatment of verbal triggers remains stipulative.

\subsection{Simons et al. (2010)}

In a recent paper Simons et al. (2010) outline a triggering and projection theory for what they term "projective meaning", which roughly covers phenomena more commonly known as presuppositions and conventional implicatures. Projective meanings in their terminology are implications that survive under the scope of an entailment canceling operator. The core of their proposal is that implications project if they do not address the Question Under Discussion: 
(10) Hypothesis about what projects and why:

a. All and only those implications of (embedded) sentences which are not at-issue relative to the Question Under Discussion in the context have the potential to project.

b. Operators (modals, negation, etc.) target at-issue content. (p. 315)

The first part of the hypothesis is based on the intuition that has been around (cf. Stalnaker 1974; Abbott 2000; Chierchia and McConnell-Ginet 2000) and is also shared by the present paper, according to which presuppositions (and conventional implicatures in the sense of Potts 2005) are typically not the main point of what is said (or at-issue, in Simons et al.'s terminology). The second part states that operators only target the main point of an utterance (cf. also Kratzer 1989 for related ideas). The main point (or at-issue content) is defined as follows:

(11) Definition of at-issueness

a. A proposition $\mathrm{p}$ is at-issue iff the speaker intends to address the QUD via ?p.

b. An intention to address the QUD via ?p is felicitous only if:

1. $? \mathrm{p}$ is relevant to the QUD, and

2. the speaker can reasonably expect the addressee to recognize this intention. (p. 323)

(12) Relevance to the QUD

a. An assertion is relevant to a QUD iff it contextually entails a partial or complete answer to the QUD.

b. A question is relevant to a QUD iff it has an answer which ontextually entails a partial or complete answer to the QUD. (p. 316)

Thus what becomes the main point of an utterance is determined by the content of the discourse and speaker intentions, without reference to grammatical constraints. Since what projects is what is not the main point, projection facts (and therefore presuppositions) are predicted to be highly context sensitive and volatile. An implication might behave like a presupposition (projective meaning) in one context, but might be part of the main point (at-issue meaning) in another, and thus not project. Let's look at an example they discuss:

(13) Background scenario: a nutritionist has been visiting first grade classrooms to talk to the children about healthy eating

Q: What most surprised you about the first graders?

A: They didn't know that you can eat raw vegetables. (p. 317)

To determine what projects, in this case one has to look at the (contextual) entailments of the statement in the scope of the matrix negation. One of these is that you can eat raw vegetables. This proposition (and the yes-no question ?p that can be formed from it) is arguably not one that is relevant to the question under discussion 
(at least if the generic statement is not also understood to be about the first graders), hence it projects. Another entailment they consider is that the first graders know that you can eat raw vegetables. This one can be intended as addressing the QUD, and is thus identified as non-projective, at-issue content. It is therefore understood to be under the scope of negation.

Some of the basic aspects of Simons et al.'s (2010) proposal are close in spirit to the present paper, in particular that presuppositions are not at issue, hence not the main point. They can also predict that presuppositions might disappear in some contexts, namely when their content is understood as addressing the question under discussion. As it was noted in the outset of this paper, such cases are indeed pervasive. However, the theory as it stands predicts such shifts with much more ease than is actually observed. The authors do notice this problem, but the proposed fix in effect gives up on predicting what projects from the meaning of utterances, at least when it comes to presuppositions of soft triggers.

Observe a variant of the previous example: According to Simons et al.'s (2010) theory, no presupposition should be generated in this case:

Q: What most surprised you about the first graders?

A: They didn't know that they have failed the exam.

In (13), the proposition that first graders have failed the exam can easily be understood (as being intended to be) addressing the QUD, at least in contexts where the exam is very easy. Therefore, it is at-issue and should not project, but this is not what we observe. So it seems presuppositions are not as easily cancelable by the context as Simons et al. (2010) would have us believe. Similar cases are easy to find with other triggers as well:

Q: What do you know about John?

B: He still didn't quit smoking.

In the above case, the implication of B's utterance that John used to smoke is clearly relevant information about John, and should therefore be addressing the QUD, and not project. But this is not what we observe, instead, the implication seems to be presupposed.

There are also cases where they predict entailments that are not presupposed to be presupposed. In (16), the utterance of B entails that somebody knows that it is raining. This entailment does not seem to be at-issue: speakers will not intend to address the QUD in (16A) by it since it is not relevant to the QUD: it does not contextually entail a partial or complete answer to the question by A, which is why a dialogue in which A's question is answered by Somebody knows that it is raining would be quite odd. Therefore the existential entailment below is predicted to be presupposed by Simons et al. (2010), contrary to fact.

(16) A: What surprised you about John?

B: He knows that it is raining.

entails: Somebody knows that it is raining. 
Simons et al. (2010) recognize that their theory over-predicts sensitivity to contextual factors, and faced with this problem say the following:

At-issueness, as we have defined it (...) is determined solely by conversational structure. Whether or not a particular (propositional) implication of an utterance is at-issue depends only on what the current QUD is. If the implication (or its negation) is a potential answer to the QUD, the proposition is at-issue; otherwise, it is not. But this runs counter to intuitions and observations that linguistic form is, at the very least, a strong indicator of projective status-hence the widely accepted view that presuppositions are conventional parts of lexical content. (...) We posit that at least some constructions or lexical items conventionally mark their content as not-at-issue. We remain agnostic as to which expressions conventionally mark at-issue status. (p. 322)

However, since examples like the above are easily constructed with any soft presupposition trigger, at the end of the day each of these will have to be conventionally marked as triggering some not-at-issue, projective material. As a result, the theory is not really telling us what projects, only that whatever projects is not atissue content.

\section{Attention and aboutness}

The central idea behind this paper is that presuppositions of soft triggers arise from the way our attention structures the informational content of a sentence. Some aspects of the information conveyed are such that we pay attention to them by default, even in the absence of contextual information. On the other hand, contextual cues or conversational goals can divert attention to types of information that we would not pay attention to by default. Either way, whatever we do not pay attention to, be it by default, or in context, is what ends up presupposed.

This two-tier view of how attention structures information is familiar from studies of vision. (see e.g. Goldstein 2009; Itti and Koch 2001; Navalpakkam and Itti 2005 among many others). A flickering light, a red dot on gray background, or seeing our own name written on a screen attracts our attention immediately in any context. These are examples that manifest the default, bottom-up processes of attention. Interestingly, when looking at a scene, visual attention is also influenced by what the scene is about: semantically more relevant cues attract attention. At the same time, when looking at a photograph we might easily overlook somebody's shadow or reflection in the water, or the lack of these, even if these occupy a comparatively large portion of the photograph. However, in a context in which shadows or reflections are made salient and relevant, suddenly we pay attention to such cues as well. These are examples of top-down, goal oriented mechanisms of attention. Further, we also tend to assume that aspects of familiar scenes that we do not pay attention to (for example shadows in a neutral context) are nevertheless there.

The grammatical analogy with vision is the following. We instinctively pay attention to information that is about the main event described by the sentence. This 
corresponds to the default, bottom-up process of attention. Any information that is also conveyed by the sentence but is not about the main event described is presupposed, unless there is some contextual factor that directs attention to this information as well. Such contextual factors correspond to top-down processes of attention. In these cases what would normally be presupposed is not presupposed any more: i.e. we have presupposition suspension. Note that what happens is not that attention is completely diverted, rather, extra information is brought under the spotlight of attention as well. This corresponds to the observation that there are no cases reported in the literature (at least to my knowledge) where context would swap the presupposed and the asserted aspects of the meaning of a soft trigger. Instead, contextual effects tend to amount to the removal of presuppositions. ${ }^{9}$

\subsection{The default main point}

The question now is, what is the default point described by a sentence and among all the myriad propositions that are entailed by a sentence, how do we find the ones that are about the main point described by the sentence?

The intuition that we want to capture is that presuppositional assertions describe complex states of events, some parts of which are independent from the main events. So what we want to achieve is to tell independent events apart: Select the main event described by the sentence, and decide what other information conveyed by the sentence describe independent events from the main one. But this is a very difficult task and cannot be easily accomplished just by looking at events themselves because of the very complex mereological structure of events. For example, is the event of raining part of the complex event of John's knowing it? If not, why not?

To simplify matters, I will map events to their event times. The idea of looking at event times instead of events themselves serves the purpose of making independence more tractable: Events that happen at different times are clearly different events. Further, in some cases, e.g. sentences involving mathematical truths (John knows that $2+2=4$ ), the possibility of invoking events is not obvious at all. However, since event times are more abstract than events, evoking event times is still possible even in these cases.

Thus I will assume that the default main point of a sentence is given by those entailments that are by nature about the event time of the matrix predicate. Propositions that describe events that are not (or do not have to be-in the sense to be introduced in Sect. 3.3) about the event time of the matrix predicate of $\mathrm{S}$ are independent, and hence presupposed. Let's illustrate the idea with a simple example. Consider (17), in which $t_{1}$ denotes the event time interval of the matrix predicate, and $t_{2}$ is some interval before $t_{1}$, given by the context. Let's look at the sentence $\mathrm{S}$ and two its (many) entailments, $\varphi$ and $\psi$ :

\footnotetext{
9 A different case of context dependency is when presuppositions are added to otherwise non-presuppositional expressions, as discussed in Schlenker (2010). These are also captured by the present mechanism, see Sect. 6.
} 
(17) $\mathrm{S}=$ John knows (at $\mathrm{t}_{1}$ ) that it was raining (at $\left.\mathrm{t}_{2}\right)$.

a. $\varphi=$ John believes $\left(\right.$ at $\left.\mathrm{t}_{1}\right)$ that it was raining $\left(\right.$ at $\left.\mathrm{t}_{2}\right)$.

b. $\psi=$ It was raining $\left(\right.$ at $\left.t_{2}\right)$.

In an intuitive sense, $\varphi$ is about the time denoted by $\mathrm{t}_{1}$, but $\psi$ is not: changing the properties of the world at $\mathrm{t}_{1}$ will not affect the truth value of $\psi$, but it might affect the truth value of $\varphi$.

For concreteness, I will assume that event times denote salient intervals whose value is assigned by the context. As such, they are rather like pronouns (cf. Partee 1973). ${ }^{10}$ In this system, predicates have an extra argument slot for time, thus what are usually assumed to be one place predicates such as intransitive verbs are going to be two place predicates, taking an individual and a time argument. Tense morphemes introduce time variables that saturate the time argument slot of predicates in the syntax. The denotation of this variable is given by the interpretation function $i$ supplied by the context, which assigns it an element from the domain of time intervals. E.g. the sentence in (18) is true iff John is tired at the time assigned to $t_{2}$ by $i^{11}$

John is tired at $t_{2}$

Now we might ask what it means for a sentence to be about the entity denoted by one of its arguments, in our case about its time argument? Exactly this notion is captured by Demolombe and Fariñas del Cerro's (2000) definition of aboutness, introduced below.

\subsection{Being about an entity}

The intuitive idea of Demolombe and Fariñas del Cerro $(2000)^{12}$ is that the truth value of a sentence that is not about an entity should not change if we change the truth value of the facts about that entity. To capture this intuition, they give a proposal that has two parts. The first is the definition of variants of an interpretation with respect to an object. Given this notion, the property of a sentence being about an object can be defined.

Definition 1 (The syntax of the language $\mathrm{L}_{\mathrm{c}}$ ) Let $\mathrm{L}_{\mathrm{c}}$ be a first order predicate calculus language, where $\mathrm{c}$ is some constant symbol. The equality predicate is not allowed in the language.

\footnotetext{
10 For convenience I further assume that the tense argument is represented in the syntax as well, though this is not crucial. cf. Kusumoto (2005) for some recent arguments for this assumption, but also Keshet (2008) for arguments against Kusumoto's position.

11 I will be agnostic about the question whether it is the past/present/future feature (presupposition) on tense variable/morpheme itself that contributes the meaning of anteriority or simultaneity (e.g. as in Partee 1973), or whether these derive from phonologically null elements that stand in some relation with tense morphemes, and give the ordering between event times (the time denoted by the tense morpheme, here: $t_{2}$ ) and evaluation times (e.g. cf. Kusumoto 2005).

12 Cf. also Demolombe and Fariñas del Cerro (2010) for a more recent exposition of the key ideas present in Demolombe and Fariñas del Cerro (2000).
} 
The primitive vocabulary of $\mathrm{L}_{\mathrm{c}}$ consists of the following:

1. A set of constants designated in the metalanguage by letters $a, b, c, \ldots$

2. A denumerably infinite set of variables $v_{1}, v_{2}, v_{3}, \ldots$ The constants and variables together constitute the terms.

3. A set of predicates, $p, q, r$, each with fixed arity

4. The logical connectives $\neg, \vee, \wedge, \rightarrow, \leftrightarrow$

5. The quantifier symbols $\exists, \forall$

6. The parentheses (,)

The set $\mathrm{F}$ of formulas of $\mathrm{L}_{\mathrm{c}}$ is defined by the following rules:

1. If $p$ is an n-ary predicate and $t$ an n-tuple of terms, then $\mathrm{p}(\mathrm{t}) \in \mathrm{L}_{\mathrm{c}}$

2. If $\mathrm{F} \in \mathrm{L}_{\mathrm{c}}$, and $\mathrm{G} \in \mathrm{L}_{\mathrm{c}}$, then $\neg \mathrm{F} \in \mathrm{L}_{\mathrm{c}},(\mathrm{F} \vee \mathrm{G}) \in \mathrm{L}_{\mathrm{c}},(\mathrm{F} \wedge \mathrm{G}) \in \mathrm{L}_{\mathrm{c}},(\mathrm{F} \rightarrow \mathrm{G}) \in \mathrm{L}_{\mathrm{c}}$, $(\mathrm{F} \leftrightarrow \mathrm{G}) \in \mathrm{L}_{\mathrm{c}}$

3. If $\mathrm{F} \in \mathrm{L}_{\mathrm{c}}$, then $(\exists \mathrm{vF}) \in \mathrm{L}_{\mathrm{c}}$ and $(\forall \mathrm{vF}) \in \mathrm{L}_{\mathrm{c}}$

4. All the sentences in $L_{c}$ are defined by the rule 1-3.

Definition 2 (Interpretation) An interpretation $\mathrm{M}$ of $\mathrm{L}_{\mathrm{c}}$ is a tuple $\mathrm{M}=\langle\mathrm{D}, \mathrm{i}\rangle$ such that

1. $\mathrm{D}$ is a non-empty set of individuals and time intervals

2. $\mathrm{i}$ is a function that assigns

(a) to each predicate symbol of arity $\mathrm{n}$ a subset of $\mathrm{D}^{n}$,

(b) to each variable symbol an element of D (As a notational convention,

I will use $t$ for variables over tense intervals, and $x$ for variables over individuals)

(c) to each constant symbol an element of D

The domain of $\mathrm{M}$ will be denoted by $\mathrm{D}_{\mathrm{M}}$ and the interpretation of $\mathrm{M}$ by $\mathrm{i}_{\mathrm{M}}$.

NB: As indicated in the previous section, verbal predicates are assumed to have a tense argument on top of any individual arguments. I will also make use of the following simplifying assumptions: (a) definite descriptions denote individuals (b) the denotation of indexicals is given by the interpretation function and their indexical content is presupposed. E.g. you has the presupposition that it can only be used felicitously if $\mathrm{i}_{\mathrm{M}}(\mathrm{you})$ denotes the addressee in the context. (c) For the purposes of calculating aboutness I will also assume that the complement of attitude predicates is absorbed into the attitude verb, so that $k n o w(x, t, p)$ is in fact a 2-place predicate know-p $(x, t)$. The reason why this is not harmful is because we are not attempting to derive the entailments of verbs from their lexical semantics-we are treating the origin of these entailments as a black box. Also, the mechanism checking aboutness only ever needs to look at the matrix tense of the sentences it examines, and not at embedded tenses. This allows turning these expressions into simple extensional predicates and ignoring the intricate semantics of attitude verbs. Note that none of the above assumptions (nor $\mathrm{L}_{c}$ in general) are meant as an adequate theory of language: they are only simplifications that allow us to abstract away from complex aspects of language that are not relevant for our purposes when calculating aboutness. 
Definition 3 (Satisfiability conditions) Let $\mathrm{M}$ be an interpretation of the language $\mathrm{L}_{\mathrm{c}}$. The truth of a formula $\mathrm{F}$ in $\mathrm{M}$ is denoted by $\mathrm{M} \models \mathrm{F}$, and is inductively defined as follows:

1. If $\mathrm{F}$ is an atomic sentence of the form $p(k)$, where $k$ is a tuple of constant or variable symbols, $\mathrm{M} \models \mathrm{F}$ iff $\mathrm{i}_{\mathrm{M}}(\mathrm{k}) \in \mathrm{i}_{\mathrm{M}}(\mathrm{p})$.

2. $\mathrm{M} \models \mathrm{F}$ and $\mathrm{M} \models \mathrm{F} \vee \mathrm{G}$ are defined from $\mathrm{M} \models \mathrm{F}$ and $\mathrm{M} \models \mathrm{G}$ as usual.

3. $\mathrm{M} \models \exists \mathrm{vF}$ iff there exists an interpretation $\mathrm{M}_{\mathrm{v} / \mathrm{d}}$ that only differs from $\mathrm{M}$ by the interpretation of the variable symbol $v$, st. $i_{M v / d}(v)$ is the element $d$ of $D_{M v / d}$ and $\mathrm{M}_{\mathrm{v} / \mathrm{d}} \models \mathrm{F}$.

Definition 4 (Variants of an interpretation with regard to an object) Roughly speaking the notion of variants of an interpretation with regard to an object denoted by constant symbol $\mathrm{c}$ is the set of interpretations $M^{c}$ that only differ from $\mathrm{M}$ by the truth assignment of atomic sentences where c appears as an argument.

Let $L_{c}$ be a first order predicate calculus language that contains the constant c and does not contain the identity predicate. ${ }^{13} \mathrm{M}^{\prime}$ is a c-variant of a model $\mathrm{M}$ iff it meets the constraints listed below:

1. $D_{\mathrm{M}^{\prime}}=D_{\mathrm{M}}$

2. $i_{\mathrm{M}^{\prime}}=i_{\mathrm{M}}$, for every variable symbol and constant symbol

3. $i_{\mathrm{M}^{\prime}}$ is defined from $i_{\mathrm{M}}$ for each predicate symbol as follows: if $p$ is a predicate symbol of arity $n$

(a) if $k$ is an n-tuple of terms of language $L_{c}$ that contain no occurrence of the constant symbol $c$, then $i_{\mathrm{M}^{\prime}}(k) \in i_{\mathrm{M}^{\prime}}(p)$ iff $i_{\mathrm{M}}(k) \in i_{\mathrm{M}}(p)$.

(b) if an element $\left\langle d_{1}, \ldots, d_{n}\right\rangle$ of $D^{n}$ is such that for every $j$ in [1,n], $d_{\mathrm{j}} \neq i_{\mathrm{M}}(c)$, then $\left\langle d_{1}, \ldots, d_{n}\right\rangle \in i_{\mathrm{M}^{\prime}}(p)$ iff $\left\langle d_{1}, \ldots, d_{n}\right\rangle \in i_{\mathrm{M}}(p)$.

$M^{c}$ will be used to denote the set of c-variant interpretations $M^{\prime}$ defined from $M$.

Suppose $\mathrm{p}$ is a unary predicate. Then the condition in 3(a) above says that the properties of the entities that are denoted by constant symbols other than $\mathrm{c}$ do not change in c-variants of M. 3(b) says that the properties of entities other than the one denoted by c do not change. These two conditions amount to almost the same thing, nevertheless they are both needed as the first (but not the second) rules out cases where some other constant $c^{\prime}$ denotes the same individual as $c$ and therefore the properties of $\mathrm{c}^{\prime}$ would also change in c-variants, the second (but not the first) rules out that properties of individuals that do not have a name change in variants.

An example: Let $L_{c}$ be a language with a unique unary predicate symbol $p$, and the constant symbols $a, b, c$. Let $\mathrm{M}$ be an interpretation of $L_{c}$ defined by: $D=\left\{d_{1}, d_{2}, d_{3}, d_{4}\right\}, i_{M}(a)=d_{1}, i_{M}(b)=d_{2}, i_{M}(c)=d_{3} \quad$ and $\quad i_{M}(p)=\left\{d_{1}, d_{3}\right.$, $\left.d_{4}\right\}$. For every variant $M^{\prime}$ in $M^{c}, i_{M^{\prime}}(p)$ contains $d_{1}$, because $i_{\mathrm{M}}(p)$ contains $d_{1}$ and $d_{1}$ is the interpretation of the constant symbol $a$, which is different from constant symbol $c$. Therefore the sentence $p(a)$ is true in every variant $M^{\prime}$. At the other extreme, there are variants $M^{\prime}$ of $M$ such that $d_{3}$ is not in $i_{\mathrm{M}^{\prime}}(p)$, because $d_{3}$ is the interpretation of $c$. In these variants $p(c)$ is false, although it is true in $M$.

\footnotetext{
13 Though cf. Demolombe and Fariñas del Cerro (2000) for some suggestions on how the identity predicate could be handled.
} 


\subsubsection{Aboutness}

Let $S$ be a sentence of language $L_{\mathrm{c}} . S$ is not about an object named by the constant symbol $c$ iff for every interpretation $M, M \models S$ iff for every interpretation $M^{\prime}$ in $M^{c}$ $M^{\prime} \models S$ :

$$
N A(S, c) \text { holds iff } \forall M\left(M \models S \text { iff } \forall M^{\prime} \in M^{c} M^{\prime} \models S\right)
$$

A sentence $S$ is about an object named by c if it is not the case that $N A(S, c)$ :

$$
A(S, c) \text { holds iff } \exists M\left(\exists M^{\prime} \in M^{c}\left(M \models S \text { and } M^{\prime} \forall S\right)\right)
$$

\subsubsection{Examples}

Now consider the following examples:

(21) $\mathrm{S}=$ Fido is tired

The sentence in (21) is about Fido, if there are two models $\mathbf{M}, \mathbf{M}^{\prime} \in M^{\text {Fido }}$, such that $\mathrm{M} \models \mathrm{S}$ and $M^{\prime} \forall \mathrm{S}$. Suppose that $\mathrm{L}$ is a language with a unique unary predicate symbol is tired, and the constant symbols Fido, John, Mary. Let $\mathrm{M}$ be an interpretation of L defined by:

1. $\mathrm{D}=\left\{\mathrm{d}_{1}, \mathrm{~d}_{2}, \mathrm{~d}_{3}, \mathrm{~d}_{4}\right\}$;

2. $\mathrm{i}_{\mathrm{M}}($ Fido $)=\mathrm{d}_{1} ; \mathrm{i}_{\mathrm{M}}($ Mary $)=\mathrm{d}_{2} ; \mathrm{i}_{\mathrm{M}}($ John $)=\mathrm{d}_{3}$

3. $\mathrm{i}_{\mathrm{M}}($ is tired $)=\left\{\mathrm{d}_{1}, \mathrm{~d}_{3}, \mathrm{~d}_{4}\right\}$

From this model, a Fido-variant $M^{\prime}$ can be defined, where $i_{M^{\prime}}$ (is tired) $=\left\{d_{3}, d_{4}\right\}$. Thus $\mathrm{M} \models \mathrm{S}$ and $\mathrm{M}^{\prime} \not \models \mathrm{S}$.

Consider now:

(22) $\mathrm{S}=$ John is tired

The example in (22) is not about Fido, because for every $\mathrm{M}^{\prime} \in M^{\text {Fido }}, \mathrm{M}^{\prime} \models \mathrm{S}$, and further for any model $\mathrm{M}$, st. $\mathrm{M} \models \mathrm{S}$, for every $\mathrm{M}^{\prime} \in M^{\text {Fido }}, \mathrm{M}^{\prime} \models \mathrm{S}$.

(23) Fido is tired or Fido is not tired

The disjunction above is not about Fido, because it is a tautology hence it is true in every model M. Interestingly,

(24) Some individual is tired

is about Fido, because there are two models $\mathrm{M}, \mathrm{M}^{\prime} \in M^{\text {Fido }}$, such that $\mathrm{M} \models \mathrm{S}$ and $\mathbf{M}^{\prime} \not \forall \mathrm{S}$ : suppose originally in our example we had $\mathrm{i}_{\mathbf{M}}$ (is tired) $=\left\{\mathrm{d}_{1}\right\}$, and $\mathrm{i}_{\mathrm{M}}^{\prime}$ (is tired) $=\emptyset$. 
Let's look at a sentence that has a tense argument as well.

\section{John is tired at $\mathrm{t}_{2}$}

The sentence in (25) is about $\mathrm{t}_{2}$, if there are two models $\mathrm{M}, \mathrm{M}^{\prime} \in \mathrm{Mt}_{2}$, such that $\mathrm{M} \models$ $\mathrm{S}$ and $\mathrm{M}^{\prime} \not \forall \mathrm{S}$. Let's add tense to our $\mathrm{L}$ above: Suppose that $L^{\prime}$ is a language with a unique binary predicate symbol is tired, and the constant symbols Fido, John, Mary and the variables $t_{1}, t_{2}$. Let $\mathrm{M}$ be an interpretation of $\mathrm{L}^{\prime}$ defined by:

1. $\mathrm{D}=\left\{\mathrm{d}_{1}, \mathrm{~d}_{2}, \mathrm{~d}_{3}, \mathrm{~d}_{4}, \mathrm{~d}_{5}, \mathrm{~d}_{6}\right\}$;

2. $\mathrm{i}_{\mathrm{M}}($ Fido $)=\mathrm{d}_{1} ; \mathrm{i}_{\mathrm{M}}($ Mary $)=\mathrm{d}_{2} ; \mathrm{i}_{\mathrm{M}}(\mathrm{John})=\mathrm{d}_{3} ; \mathrm{i}_{\mathrm{M}}\left(\mathrm{t}_{1}\right)=\mathrm{d}_{5} ; \mathrm{i}_{\mathrm{M}}\left(\mathrm{t}_{2}\right)=\mathrm{d}_{6}$

3. $\mathrm{i}_{\mathrm{M}}($ is tired $)=\left\{\left\langle\mathrm{d}_{1}, \mathrm{~d}_{6}\right\rangle,\left\langle\mathrm{d}_{3}, \mathrm{~d}_{6}\right\rangle,\left\langle\mathrm{d}_{4}, \mathrm{~d}_{5}\right\rangle\right\}$

From this model, a $\mathrm{t}_{2}$-variant $\mathrm{M}^{\prime}$ can be defined, where $\left\langle\mathrm{d}_{3}, \mathrm{~d}_{6}\right\rangle \notin \mathrm{i}_{\mathrm{M}}^{\prime}$ (is tired). Thus $\mathrm{M} \models \mathrm{S}$ and $\mathrm{M}^{\prime} \not \models \mathrm{S}$ and so the sentence is about $\mathrm{t}_{2}$. Note that (25) is also about John, but it is not about Fido or $\mathrm{t}_{1}$ : removing $\left\langle\mathrm{d}_{1}, \mathrm{~d}_{6}\right\rangle$ or $\left\langle\mathrm{d}_{4}, d_{5}\right\rangle$ from $\mathrm{i}_{\mathrm{M}^{\prime}}$ (is tired) will not affect the truth of (25) in the model. In c-variant models it is not only the properties of $c$ itself that are allowed to differ, but the truth of sentences that contain $c$ as an argument.

\subsection{Triggering mechanism—default version}

The definition above defines what it means for a sentence $S$ to be about an object. In principle however we are interested in whether propositions (entailments of $S$ ) are about an object. The relationship between the two is somewhat indirect: we need to check whether sentences that can be used to express a proposition are about an object. If yes, I will assume that the proposition expressed by the sentence is about that object as well. ${ }^{14}$

We are now in the position to give the first version of the default triggering mechanism for soft presuppositions:

\section{Presupposition triggering (1st version, to be revised)}

Entailments of a sentence $\mathrm{S}$ that can be expressed by sentences that are not about the event time of the matrix predicate of $\mathrm{S}$ are presupposed.

Being about is to be understood as defined in the preceding subsection. This predicts (17): the (sentence expressing the) entailment that John believes at $t_{1}$ that it is raining at $t_{2}$ is about the matrix event time $t_{1}$, hence not presupposed, while (the sentence expressing) the entailment that it is raining at $t_{2}$ is not about the matrix event time $t_{1}$, hence it is presupposed. (The reasoning that predicts this as well as further examples will be spelled out in more detail in Sect. 4.)

Yet with this simple approach the obvious question arises: what about sentences such as (27), where the embedded proposition and the matrix proposition are assumed to be true at the same time? The proposal in (26) predicts that the embedded

\footnotetext{
14 One limitation of this approach, pointed out to me by C. Potts, is that only propositions that can be expressed in a sentence can be presupposed. For the moment the present paper has to accept this.
} 
proposition in (27) is not independent from the main assertion, and therefore, not presupposed, contrary to fact:

(27) John knows (at $\left.\mathrm{t}_{1}\right)$ that it is raining (at $\mathrm{t}_{1}$ ).

a. $\varphi=$ John believes $\left(\right.$ at $\left.\mathrm{t}_{1}\right)$ that it is raining (at $\left.\mathrm{t}_{1}\right)$.

b. $\psi=$ It is raining $\left(\right.$ at $\left.\mathrm{t}_{1}\right)$.

What we need is a way to distinguish accidental co-temporaneity from non-accidental one. In the above example, though it so happens that the embedded proposition and the matrix proposition are true at the same time, this is only an accident, it could be otherwise. But the co-temporaneity of the matrix time of $\varphi$ with the matrix time of $\mathrm{S}$ is not an accident, but follows from the lexical interpretation of know. So we need a method of distinguishing accidental and non-accidental co-temporal dependencies.

To remedy this, I will assume that the default presupposition triggering mechanism looks beyond the actual sentence and assesses the properties of alternative sentences that I call temporal-alternatives (or just $\mathrm{T}$-alternatives for short). T-alternatives are obtained by replacing the temporal arguments of the matrix and embedded predicates with different ones. ${ }^{15}$ More precisely, we replace the temporal variables with ones which the assignment function maps to different intervals than the original time of the matrix predicate. E.g.:

John knows (at time $\mathrm{t}_{1}$ ) that it was raining (at time $\mathrm{t}_{1}$ )

T-alternative: John knows (at time $\mathrm{t}_{1}$ ) that it was raining (at time $\mathrm{t}_{2}$ )

John managed (at time $\mathrm{t}_{1}$ ) to solve the exercise (at $\mathrm{t}_{1}$ )

T-alternative: *John managed (at time $\mathrm{t}_{1}$ ) to solve the exercise (at $\left.\mathrm{t}_{2}\right)$

Let's say that $\mathrm{p}$ and $\mathrm{p}^{\prime}$ are corresponding entailments if they can be expressed by sentences that only differ in their temporal arguments. Take an entailment $\mathrm{p}$ of S. If there is a well formed T-alternative $S^{\prime}$ to $S$ such that the corresponding entailment to $\mathrm{p}$ (namely $\mathrm{p}^{\prime}$ of $\mathrm{S}^{\prime}$ ) can be expressed by a sentence that is not about the event time of the matrix clause of $S^{\prime}$, then I will say that $p$ is only accidentally about the matrix event time of S. Let's look at the examples above. In (28), the entailment that it was raining (at time $\mathrm{t}_{1}$ ) of the original sentence is only accidentally about $\mathrm{t}_{1}$, because there is a T-alternative (John knows (at time $t_{1}$ ) that it was raining (at time $\mathrm{t}_{2}$ )) whose corresponding entailment (that it was raining at $t_{2}$ ) is not about the matrix tense of the T-alternative. On the other hand, (29) does not have a well formed T-alternative where the two temporal arguments differ (cf. Karttunen 1971a and Sect. 4.1.2 on temporal restrictions of implicatives): for this reason the entailment of the original sentence in (29) that John solved the exercise at $t_{1}$ is non-accidentally (i.e. necessarily) about the matrix event time.

15 Moreover, quantified temporal arguments might be replaced with non-quantified ones in T-alternatives. For example John knows that some times are better than others (example due to Tim Williamson (pc)) might have as a $\mathrm{T}$-alternative John knows that $\mathrm{t}_{4}$ is better than $\mathrm{t}_{6}$. 
We are now in the position to formulate a revised version of the default triggering mechanism for soft triggers:

\section{Presupposition triggering (2nd version, to be revised)}

Entailments of a sentence $\mathrm{S}$ that can be expressed by sentences that are not necessarily about the event time of the matrix predicate of S (i.e. they are either not about it, or only accidentally so) are presupposed.

This now makes correct predictions about (27b) as well: this entailment is predicted to be presupposed because although it is about $t_{1}$, it is only accidentally so.

\subsection{Triggering mechanism-context sensitive version}

Besides the default, grammatically defined main point, it is possible that the context or the intentions of the participants of the conversation raise interest in aspects of the entailed meaning of the sentence that would otherwise "pass under the radar", and be presupposed. In Sect. 5 I will suggest two ways in which this might happen: by evidential verbs and by focus. This is not intended as an exhaustive list, indeed it is likely other factors will turn out to be relevant as well in the future.

One factor that can bring extra elements under the spotlight of attention is focus. As Beaver (2004) observes, (31) does not suggest that the student has plagiarized his work:

(31) If the TA discovers that [your work is plagiarized $]_{\mathrm{F}}$, I will be [forced to notify the Dean] (Beaver 2004, slightly modified)

Focus is usually taken to be the part of a sentence that conveys the new or highlighted information, thus the information that directly answers a background question. In this sense, focus grammatically signals the presence of a background question. I will propose that grammatically marked background questions can introduce a secondary (or pragmatic) main point. Secondary main points concern the event time of the sentence expressing the most direct proposition that answers the background question. The presupposition triggering mechanism looks both at the default (grammatical) and the secondary (pragmatic) main points and requires the presupposition to be independent from both of these. This derives the above data in the present framework.

Presupposition triggering ( $3 \mathrm{rd}$, final version)

Entailments of a sentence $S$ that can be expressed by sentences that are neither necessarily about the event time of the matrix predicate of $\mathrm{S}$ nor about the event time of the sentence expressing the most direct answer to the (grammatically signaled) background question are presupposed.

Put more simply, the proposal above requires that presuppositions be independent from both the default and the secondary (pragmatic) main points. Secondary main points can be introduced by grammatical markers such as focus and evidential verbs (and presumably others). In (31), focusing the embedded clause indicates that the background question is What will I discover? The direct answer to this question is a 
proposition, namely the proposition denoted by the embedded clause your work is plagiarized. The pragmatic, secondary main point therefore concerns the information that is about the tense argument of the sentence expressing this proposition, i.e. the tense argument of the embedded clause. For this reason, the information conveyed by the embedded clause is not independent from the secondary main point, and is not predicted to be presupposed. In most cases however there is either no grammatically signaled secondary main point, or this is the same as the default main point, and thus no contextual suspension of presupposition is observed.

\section{The bottom-up process: some core examples}

This section describes the default, bottom-up process, the output of which might be modified be taking into consideration the effects of contextual, top-down processes. Such contextual factors will be discussed in more detail in Sect. 5.

\subsection{Factive presuppositions}

I now address in more detail how the presuppositions of factive verbs can be derived. The example I look at in detail is the verb know, but it will be shown that the same analysis carries over to the whole class of factive verbs. Some other members of this class in English include realize, discover, notice, recognize, find out, remember, forget, be aware that, admit, intuit and a subclass of sensory factives sense, see, smell, hear, detect, observe. A major subclass of factive verbs is the class of emotives, factive verbs used primarily to convey the subject's emotional attitude towards information. This class, examined in Sect. 4.1.3, includes predicates such as regret, be annoyed, be upset, be glad, be happy, be ecstatic. In Sect. 4.1.4 I introduce cross-linguistic data from Catalan, Greek and Hungarian that have been taken to show that factivity is also connected to certain grammatical features and show how the proposal in this paper can predict them.

\subsubsection{Know}

Let's come back to (17), repeated below:

John knows (at time $t_{1}$ ) that it is raining (at time $t_{2}$ )

The presupposition triggering mechanism looks at the set of lexical (or "commonsense") entailments. ${ }^{16}$ These entailments are not entailments of predicates, but

\footnotetext{
${ }^{16}$ Is not necessary to look at logical entailments of S, i.e. entailments that can be derived independently of the content of S, e.g. S $\vee$ Q. On the one hand they are likely not salient candidates for presuppositions, precisely because they arise independently from the content of S. But even if they were candidates for presuppositions, the present theory would make correct predictions about them, this is because if $\mathrm{S}$ is atomic and about some time $t$, then its non-tautological logical entailments are also about t. Here is why. Take a model $\mathrm{M}$ that $\mathrm{M} \forall \forall \mathrm{S}$ and $\mathrm{M} \forall \forall \mathrm{Q}$. Since $\mathrm{S}$ is about $\mathrm{t}$, there is an $\mathrm{M}^{\prime}$ which is a $\mathrm{t}$-variant of $\mathrm{M}$ st. and $\mathrm{M}^{\prime} \models \mathrm{S}$. Since $\mathrm{S}$ logically entails $\mathrm{Q}, \mathrm{M}^{\prime} \models \mathrm{Q}$. Thus no non-tautological logical entailment is predicted to be presupposed. Tautological entailments of $\mathrm{S}$ are predicted to be presupposed, as these are never about the matrix time, but this is harmless.
} 
entailments of sentences. Lexical entailments are not given in a formal way: they are only available to speakers by inspecting their intuitions about the lexical meaning of predicates and the meaning of S itself. Below is a list of some of the intuitively plausible lexical entailments of (33):

(34) Some lexical entailments of John knows at $t_{1}$ that it is raining at $t_{2}{ }^{17}$

a. John knows at $t_{1}$ that it is raining $t_{2}$

b. John believes at $t_{1}$ that it is raining at $t_{2}$

c. It is raining at $t_{2}$

d. It is humid at $t_{2}$

e. John's belief is justified at $\mathrm{t}_{1}$

f. $\exists$ t, st. John knows at $\mathrm{t}$ that it is raining at $\mathrm{t}_{2}$

NB: It is not claimed here that a sentence such as (33) can be 'factorized' into its constituent lexical entailments, nor is it assumed that there is a solution to the equation John knows that $p=$ John believes that $p \wedge p \wedge X$. (cf. e.g. Williamson 2002; Yablo 2008 etc. on the dangers of such an assumption.) The only claim made is that speakers have intuitive access to plausible lexical entailments. The above list merely provides examples of such entailments and is not meant to be an exhaustive definition of the meaning of S.

Which of the above entailments, if any, are predicted to be presupposed? According to the definition of presupposition triggering above, those entailments of (33) will be predicted to be presupposed (by the default mechanism) that are expressed by sentences that are not necessarily about the event time of the matrix predicate of (33). Assuming that $t_{1}$ and $t_{2}$ pick out non-overlapping tense intervals, (34c) is not about $t_{1}$ : changing the properties of the world at $t_{1}$ will not influence the truth of $(34 \mathrm{c})$. More precisely, there are no models $\mathrm{M}, \mathrm{M}^{\prime} \in M^{t 1}$ such that $\mathrm{M} \models$ (34c) and $\mathbf{M}^{\prime} \not \forall(34 \mathrm{c})$. The same is true for (34d), which also expresses an entailment of $(34 c)$. Therefore, $(34 c, d)$ are predicted to be presupposed by the default triggering mechanism.

However, changing the properties of the world at $\mathrm{t}_{1}$ will influence the truth of (34a,b,e). Take (34b). It is easy to see that there will be two models $M, M^{\prime} \in M^{t 1}$ such that $\mathbf{M} \models(34 \mathrm{~b})$ and $\mathbf{M}^{\prime} \not \models(34 \mathrm{~b})$ : simply take a model $\mathbf{M}$ st. $\mathbf{M} \models(34 \mathrm{~b})$, form a $\mathrm{t}_{1}$ variant $\mathrm{M}^{\prime}$ in which John does not have the belief in question: it follows that $\mathbf{M}^{\prime} \not$ (34b). The same reasoning applies to $(34 \mathrm{a}, \mathrm{e})$ as well. But we are not done yet, it also needs to be checked that the latter three entailments are not accidentally about the matrix time of the sentence. For this we need to check whether we can find a Talternative $S^{\prime}$ of (33) the corresponding entailments of which are not about the matrix event time of $S^{\prime}$. However, this is not the case, as the time of the three entailments in question is crucially the same as the matrix tense of the sentence: e.g. we cannot derive valid belief-entailments of knowledge that are true at a different

\footnotetext{
17 Strictly speaking, as mentioned in Sect. 3.2., the syntactic representation of the sentence that the aboutness definition works with is one where the complement is absorbed into the predicate: John knowsit-is-raining-at- $t_{2}$ at $\mathrm{t}_{1}$.
} 
time than the knowledge. Therefore the T-alternatives of (33) will preserve the property that their entailments corresponding to $(34 \mathrm{a}, \mathrm{b}, \mathrm{e})$ will be about the matrix time of the T-alternative. For this reason, the entailments expressed by $(34 \mathrm{a}, \mathrm{b}, \mathrm{e})$ are not predicted to be presupposed by the default triggering mechanism.

The existential entailment in (34f) that we get by replacing the matrix tense argument in the original sentence by an existentially bound tense variable is also about the matrix tense: this is because, as discussed in the previous section, according to Demolombe and Fariñas del Cerro's (2000) definition of aboutness existential statements are about every individual in the domain: hence (34f) is about every tense interval in the domain. Thus the existential entailment is also not predicted to be presupposed by the present mechanism. ${ }^{18}$

As was already mentioned in the previous section, we also need to look at examples such as (35), where the embedded and the matrix tense happen to be the same.

(35) Lexical entailments of: John knows at $t_{1}$ that it is raining at $t_{1}$

a. John knows at $t_{1}$ that it is raining $t_{1}$

b. John believes at $t_{1}$ that it is raining at $t_{1}$

c. It is raining at $t_{1}$

d. It is humid at $t_{1}$

e. John's belief is justified at $\mathrm{t}_{1}$

f. $\exists$ t, st. John knows at $\mathrm{t}$ that it is raining at $\mathrm{t}$

As for (35a,b,e,f) the reasoning presented above will go through as before. What is interesting is the case of $(35 \mathrm{~d}, \mathrm{c})$. The default presupposition triggering mechanism states that those entailments of (34) will be predicted to be presupposed that are expressed by sentences that are not about, or only accidentally about the event time of the matrix predicate of (34). An entailment $\mathrm{p}$ is only accidentally about the matrix tense of $S$ if there is a well-formed alternative $S^{\prime}$ to $S$ such that the corresponding entailment $\mathrm{p}^{\prime}$ of $\mathrm{S}^{\prime}$ can be expressed by a sentence that is not about the event time of the matrix clause of $S^{\prime}$. This is indeed the case with (35): the sentence in (34) is its T-alternative, and the corresponding entailments to $(35 \mathrm{c}, \mathrm{d})$, namely $(34 \mathrm{c}, \mathrm{d})$ are indeed not about the matrix event time of (34), as it was shown above. Therefore, $(34 \mathrm{c}, \mathrm{d})$ are only accidentally about the matrix event time, and thus the propositions they express are predicted to be presupposed.

As mentioned in the outset, the presuppositions of other factive verbs such as forget, beware that, realize, etc. can be predicted in the same way as described above for know. Notice also that the present approach derives presuppositions from entailments. Contrasting the verb know with the verb believe, the latter is not factive simply because it does not entail the truth of its embedded complement. Of course one might ask why this difference in entailments exists. But this is a question

\footnotetext{
18 Note that T-alternatives only operate on the original sentence: Although they can replace quantified tense variables with non-quantified ones in the alternative, the resulting entailments then are computed as normal from the T-alternative. Thus the corresponding entailments to (34f) will also be existential statements.
} 
concerning concept formation, and is beyond the scope of what a triggering theory might hope to achieve.

\subsubsection{Implicative verbs}

It is useful to contrast factive verbs with another class of veridical predicates, implicative verbs. As Karttunen (1971a) has showed, implicative predicates such as manage, remember, see fit are veridical, but they do not presuppose their complement. $^{19}$

(36) a. John managed to solve the problem.

b. John saw fit to apologize.

c. John remembered to lock the door.

Interestingly, as Karttunen notes, the tense of the embedded predicate is not independent of the matrix tense, in the sense that it cannot be modified by independent temporal adverbials. Cf. the following examples:
a. \#John managed to solve the problem next week.
b. \#John saw fit to arrive the day after tomorrow.
c. \#John remembered to lock his door tomorrow.

The above facts contrast with other veridical predicates that combine with infinitival clauses, where such modification is available:

John was happy to arrive tomorrow.

Intuitively it is clear why we observe this restriction: managing to do something and doing it are really the same event, and therefore the two cannot be modified by independent temporal (or spacial) adverbials. This means that in the case of implicative verbs the temporal argument of the embedded clause is keyed to the tense of the matrix verb. For this reason, the sentences above do not have a wellformed T-alternative in which the matrix and the embedded tense are evaluated at different time intervals. Given this lexical property of implicatives, the embedded complement of implicative verbs is always about the matrix tense and is therefore not predicted to be presupposed by the present system. ${ }^{20}$

\subsubsection{Emotive factive verbs}

The exact nature of emotive factive verbs such as regret has been a matter of some controversy, with some researchers suggesting that they might not belong to the

19 Thanks to Jacopo Romoli and Kyle Rawlins (pc.) for bringing this issue to my attention.

20 A similar analysis might be available for examples such as force, arrange, in which cases the time of the embedded clause is also not independent from the matrix one: in particular, the event time of the embedded clause cannot precede (and in some cases, even coincide with) the event time of the matrix predicate. 
class of true factive verbs. This section argues that they are factive after all and fall under the scope of the present theory.

Traditionally, emotive factives verbs were assumed to be just like cognitive factives in presupposing the truth of their complement (cf. Kiparsky and Kiparsky 1970; Karttunen 1971b). Examples such as (39) provide good reason for this: The statement that these predicates are factive is in accordance with the intuition that from (39a) one tends to infer that it is raining and that (39b) seems to be contradictory.

a. I doubt that John regrets that it is raining

b. \#It is not raining but John regrets that it is raining.

However, it has been suggested that emotive factives only presuppose that the subject believes the truth of the embedded proposition (cf. e.g. Klein 1975; Schlenker 2003; Egré 2008). Examples such as (40), first put forward by Klein (1975), are often cited to back up this claim.

(40) a. Falsely believing that he had inflicted a fatal wound, Oedipus regretted killing the stranger on the road to Thebes (Klein 1975; quoted in Gazdar 1979, p. 122)

b. John wrongly believes that Mary got married, and he regrets/is enraged that she is no longer single (Egré 2008, based on Schlenker 2003)

In these examples even though the first conjunct entails the falsity of the complement of regret, the sentences are acceptable, which was taken to argue by some of the above authors that emotive factives are not really factive.

It seems to me that this conclusion is premature, and a factive analysis can be defended. Following Gazdar (1979), it might be assumed that Klein's (1975) example above involves free indirect speech. Thus it reports an attitude of a subject towards facts as perceived by him. This means that the implications of (40a) do not have to be shared by the speaker, which accounts for the lack of veridicality in this example. Thus, according to Gazdar, (40a) is acceptable because it reports a situation in which Oedipus is saying to himself "I killed that stranger". He points out that similar examples are possible with aware:

(41) Falsely believing that he had inflicted a fatal wound, Oedipus became aware that he was a murderer.

Under the right conditions it is not hard to construct cases analogous to (40b) and (41) with know as well:

(42) a. John suffers from paranoia. He falsely believes that the police is spying on him and what is more he knows they are listening to his phone calls.

b. The keys were not in the drawer but she knew that they were there, so she foolishly kept on searching. 
c. It's not what he doesn't know that bothers me, it's what he does know for sure but just isn't true. [Will Rogers about Ronald Reagan, from Yablo 2008]

All these cases become acceptable once they are understood as reporting a firm belief or feeling of "knowledge" on somebody's part. In this sense they are analogous to the free indirect discourse cases discussed above. This argues in favor of the possibility that regret and emotive factive verbs are not in principle different from true factive verbs. This conclusion is also supported by the observation that despite there being examples such as (40b), examples such as (39) are not acceptable either, which argues that regret (also) has a factive presupposition.

It might also be a possibility however that (at least in the case of some) emotive factives the inference about the subject's belief state is also independently presupposed. One fact that goes in this direction, pointed out to me by Jacopo Romoli (p.c.), is that (43a) is acceptable as opposed to (43b):

a. I will later regret that I did not tell the truth.
b. \#I will later know that I did not tell the truth.

The example in (43a) indicates that emotive factives such as regret imply that the onset of the belief state is earlier than the regretting itself. The entailment that is true before the matrix event time is predicted to be presupposed by the present account, because it is not about the matrix event time. From this presupposition, the hearers might pragmatically derive that the subject has the same belief at the event time as well, which gives rise to the implication that the subject believes the truth of the complement as well. ${ }^{21}$

\subsubsection{Factivity cross-linguistically}

It has been observed in a number of languages in connection with factive verbs that the linguistic form of the complement makes a difference with respect to factivity ${ }^{22}$ (Cf. Quer 2001; Giannakidou 1999, 2009). For example in Catalan, some factive verbs can take complements both in the indicative and in the subjunctive. Factive presuppositions only arise in the latter case (cf. Quer 2001). Similarly, in Greek, some verbs such as emotive factives allow embedded complements with both the complementizer oti and the complementizer $p u$. The truth of the complement is only presupposed in the latter case (cf. Varlokosta 1994; Roussou 2010; Ginzburg and

\footnotetext{
21 An anonymous reviewer asks why verbs such as surprise do not presuppose that the subject expected (at some prior time) the negation of the embedded proposition to hold. However, it seems that what is entailed in this case is at most that the subject did not expect p. This is shown by examples such as "Bill was surprised to be mugged on the beach" which can be true if Bill simply had no expectations concerning mugging. What events (if any) are described by negative statements such as the one above is a difficult issue, see Kratzer (1989) for discussion. I believe though that rather than entailing the lack of expectations at a time prior to the event time of surprise, what surprise really entails is that the subject believes (at the time of being surprised) that $\mathrm{p}$ is/was an unlikely thing to happen. This entailment is not predicted to be presupposed by my account.

22 I would like to thank an anonymous reviewer for bringing these facts to my attention.
} 
Kolliakou 1997; Giannakidou 1998, 1999, 2009). In Hungarian, the matrix sentence with the main verb tud 'know' might contain an anaphoric pronoun that introduces the embedded clause. Depending on the nature of this pronoun, the truth of the complement is either presupposed or not.

Let's take a look at the data:

(44) Catalan (Quer 2001, p. 107)

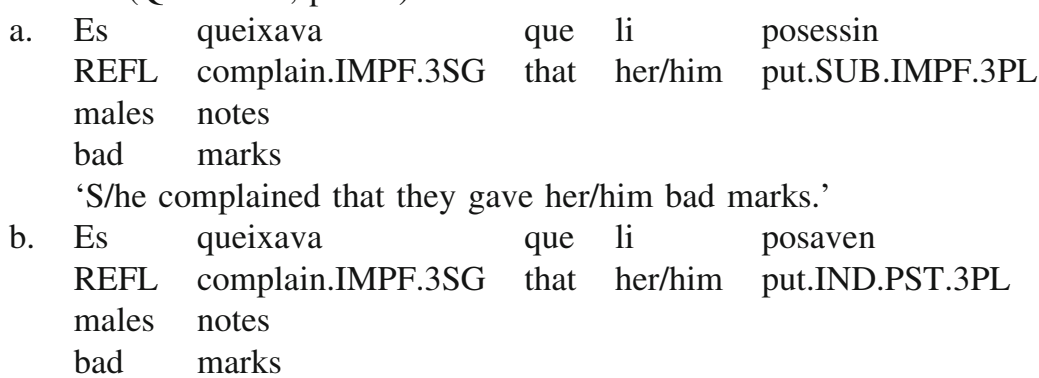

'S/he complained that they gave her/him bad marks.'

Quer (2001) notes that (44b), in which the complement clause is in the indicative, can be felicitously continued with "but s/he wasn't right: they always gave her/him reasonable marks". This is impossible in the case of (44a), where the complement is in the subjunctive. This shows that (44a) entails the truth of the complement clause, but (44b) does not. When the complement is entailed, as in (44a), it is also predicted to be presupposed in the same way as the examples in the previous sections. When the complement is not entailed, the factive presupposition does not arise.

Similar data have been discussed in Greek, except in this case the grammatical difference is in the complementizer selected. Many verbal triggers in Greek can select for either the complementizer oti or the complementizer $p u$, cf. Varlokosta (1994), Roussou (2010), Ginzburg and Kolliakou (1997), Giannakidou (1998, 1999, 2009). Only sentences where the complement is introduced by $p u$ are factive:

(45) Greek

\begin{tabular}{|c|c|c|c|c|}
\hline $\begin{array}{l}\text { O } \\
\text { The }\end{array}$ & $\begin{array}{ll}\text { Janis } & \text { paraponethike } \\
\text { John } & \text { complained. } 3 \mathrm{sg}\end{array}$ & $\begin{array}{l}\text { oti } \\
\text { that.IND }\end{array}$ & $\begin{array}{l}\text { ton } \\
\text { him }\end{array}$ & $\begin{array}{l}\text { ksexasa. } \\
\text { forgot.1sg }\end{array}$ \\
\hline 'John & complained that I forgo & him.' & & \\
\hline $\begin{array}{l}\text { O } \\
\text { The }\end{array}$ & $\begin{array}{ll}\text { Janis } & \text { paraponethike } \\
\text { John } & \text { complained. } 3 \mathrm{sg}\end{array}$ & $\begin{array}{l}\mathrm{pu} \\
\text { that.IND }\end{array}$ & $\begin{array}{l}\text { ton } \\
\text { him }\end{array}$ & $\begin{array}{l}\text { ksexasa. } \\
\text { forgot.1sg }\end{array}$ \\
\hline
\end{tabular}

The above two sentences differ both in what they entail and what they presuppose. (45a), that contains the complementizer oti, could be followed by "But he is wrong, I did not forget him". This is not possible in the case of the pu-complement in (45b). ${ }^{23}$

\footnotetext{
23 Thanks to Sabine Iatridou, Elena Anagnostopoulou, George Tsoulas and Eirini Kotsovili for contributing their native judgments. George Tsoulas notes that this pattern is clearly the general tendency, but that some variation in the judgments might exist.
} 
This shows that the truth of the oti-complement is not entailed, but the truth of the $p u$ complement is entailed.

In Hungarian too factivity might depend on something other than the predicate, at least in the case of know and perception verbs such as see. In this language, verbs that select for a clausal complement might govern an anaphoric pronoun that refers to the clausal complement. Normally this pronoun is the demonstrative azt 'it/that', and it can remain unpronounced. In some cases, another anaphoric pronoun úgy 'so' is possible as well. Complements introduced with this anaphor are never entailed, not even in the case of factive verbs. ${ }^{24}$ As in the previous cases, only (46a) is factive.

(46) Hungarian

a. Péter (azt) tudja, hogy János elment a buliba
Peter it knows that Janos went the party.Iness
'Peter knows that John went to the party.'
b. Péter úgy tudja, hogy János elment a buliba
Peter so knows that Janos went the party.Iness
'Peter believes (based on some reasonable evidence) that John went
to the party.'

One interesting question that the above facts pose is why the linguistic form makes a difference with respect to what the sentences entail. Since the present account does not attempt to predict why lexical entailments arise, this paper has nothing to say about this question. Another question is, given that we observe the above entailment patterns, can the present account correctly predict which examples will be presuppositional. This easier question we can answer affirmatively. ${ }^{25}$ In all of the cases mentioned above, when the truth of the complement is not presupposed, it is not entailed either. When it is entailed, it is presupposed as well. The approach in this paper for these data is straightforward: the grammatical differences mentioned above determine, for the given language, whether the complement is entailed or not. When it is entailed, the triggering mechanism kicks in, and flags the entailment as presupposed as well.

\subsection{Change of state verbs and achievements}

The section first looks at regular change of state verbs such as stop, after which I turn to examining achievement verbs such as win and cognitive change of state verbs such as discover. As in the previous discussion, the reasoning presented in

\footnotetext{
${ }^{24}$ It is not the case though that complements introduced with azt 'it/that' are always entailed, e.g. hisz 'believe', gondol 'think' can also stand with azt 'it/that', without entailing the truth of their complements.

25 But note that lexical accounts might have a way for accounting for these facts as well. Suppose that there is no difference in the presuppositionality of the verb per se, in all the cases the truth of the complement is presupposed. This complement however could be interpreted (because of a grammatical property introduced by mood or the complementizer) as non-actual. In this case what would be presupposed is essentially just a modal statement, which could be easily satisfied in most contexts and would not give rise to factivity as normally understood.
} 
connection with these predicates will carry over to the whole class of change of state predicates, as well as achievement verbs with a preparatory stage such as win. ${ }^{26}$

As it was argued above, to predict which entailments of the sentence will be presupposed, we only need to consider the set of lexical entailments. Consider now (47), in which $t_{1}$ denotes the event time of the predicate, in this case the time of the stopping. Let's assume that the lexical entailments of (47) are as follows:

(47) John stopped smoking at $t_{1}$

a. John does not smoke at $\mathrm{t}_{1}$

b. John smoked at $t_{2}$ (where $t_{2}$ is some contextually given interval before $\mathrm{t}_{1}$ )

c. John stopped smoking at $t_{1}$

The event time of $\mathrm{S}$ is denoted by $\mathrm{t}_{1}$. Its denotation is given by the interpretation function $i$, which assigns it an element from the domain of time intervals. In this example, the event time denotes the interval that starts just before the onset of nonsmoking, and goes on for a certain, potentially very short time. In some other cases, it might be reasonable to assume that the event time also includes a longer segment of the stage where the previous activity is still going on. This second option might be more intuitive with gradual transitions, e.g. stop the car. ${ }^{27}$ However, even in this second case the sentence also entails that the previous state held before the event time. Notice that this contrasts with the inference that the final state continues to hold, which is not an entailment. This is shown by the difference in the acceptability of the examples in (48) below.

(48) a. \#John stopped smoking, but he has never smoked before.

b. John stopped smoking, but then he started again.

In the case of change of state verbs some entailments are lexically specified to be true at some time other than the event time. This is what happens in (47b), where the lexical entailment that John used to smoke at some time preceding the event time comes from the lexical semantics of the change of state verb. Since this is entailment is true at some interval the precedes the event time $t_{1}$ it is not about $t_{1}$ : changing the properties of the world at $t_{1}$ will not influence the truth of (47b). More precisely, there are no models $\mathrm{M}, \mathrm{M}^{\prime} \in \mathrm{M}^{t 1}$ and $\mathrm{M} \models(47 \mathrm{~b})$ and $\mathbf{M}^{\prime} \not \models(47 \mathrm{~b})$. Therefore, the proposition expressed by (47c) is predicted to be presupposed by the default triggering mechanism. On the other hand, (47a) and (47c) are not predicted to be presupposed as these are clearly about the event time $t_{1}$ : changing the properties of the world at $t_{1}$ will influence the truth of (47a,c). Take (47a). It is easy to see that there will be two models $M, M^{\prime} \in M^{t 1}$ such that $M \models(47 a)$ and $M^{\prime} \not \forall(47 a)$ : simply take a model $\mathrm{M} \models(47 \mathrm{a})$, form a $\mathrm{t}_{1}$ variant $\mathbf{M}^{\prime}$ in which John does not smoke at $\mathrm{t}_{1}$ : then $\mathrm{M}^{\prime} \not \forall(47 \mathrm{a})$. The same reasoning applies to $(47 \mathrm{c})$, which is just the

\footnotetext{
26 The latter were argued to be presuppositional by Simons (2001) and Abusch (2010).

27 Further, it might not be possible to pin down the exact moment when the 'change' starts: as it is shown very nicely in Landman (1991, Chap. 4), such attempts inevitably run into the vagueness problem.
} 
sentence itself. Therefore the propositions expressed by $(47 \mathrm{a}, \mathrm{c})$ are not predicted to be presupposed.

It might be the case that an entailment of a sentence can be expressed by two sentences that differ in their arguments. For example, the sentences in (49) might be expressing contextually equivalent entailments of (47).

a. John smoked at some time $t_{2}$ before $t_{1}$.

b. John smoked at some time $t_{2}$. (where $t_{2}$ is interpreted as an interval not overlapping with $\mathrm{t}_{1}$ )

Interestingly, (49a) is technically about the matrix tense $t_{1}$ of (47), but not (49b). Thus, the triggering mechanism will predict that the entailment expressed by (49b) is presupposed, but it will not predict that the entailment expressed by (49a) is presupposed, even though these entailments might be contextually equivalent. But this is not contradictory, because the triggering mechanism only makes positive predictions, not negative ones. It predicts for a proposition $\mathrm{p}$ that it is presupposed, if that is the case, and says nothing about propositions that are not predicted to be presupposed. In particular, it does not make any claim that a proposition that is not predicted to be presupposed cannot be presupposed in some other way: this might happen if some other mechanism kicks in, or as in the above case, if a contextually equivalent proposition can be expressed by a sentence that is not about the matrix time, and is therefore predicted to be presupposed. Notice also that the triggering mechanism says that entailments are presupposed if there is a sentence expressing them that is not necessarily about the matrix (or secondary) event time.

The theory also makes the prediction that if two aspectual verbs were to differ only in the lengths of the interval denoted by the event time, their corresponding presuppositions should also differ. This prediction seems to be borne out as well. The following are examples from Hungarian:
a. János eljött
'John came'
b. János megjött
'John came/arrived'

In the above examples the overall meaning is approximately the same, but there is a difference (resembling the difference btw. come and arrive in English, respectively) in that the event time seems to denote a different interval.
a. Tegnap János eljött
'Yesterday John came'
b. Tegnap János megjött
'Yesterday John came/arrived'

In the case of eljött, modification with yesterday suggests that the whole event of John leaving the point of departure and arriving at target location happened yesterday and is not compatible with a scenario in which he departed weeks ago. 
In contrast, if yesterday modifies a sentence with megjött it suggests that the ending phase of John's trajectory happened yesterday, but is compatible with him departing weeks ago. Correspondingly, the presuppositions of the two examples are different too, as predicted: The negation of (51a) suggests that John stayed at home, while the negation of (51b) suggests that he left home.

\subsubsection{Achievement verbs and presuppositions about earlier stages}

The present proposal also predicts that inferences about preparatory stages of achievement verbs such as win will also end up being presupposed. (cf. Simons 2001; Abusch 2010). For example the sentences in (52) seem to presuppose that John participated in the race.

a. John did not win the Road Race.

b. If John did won the Road Race, he's got more victories than anyone else in history. (from Abusch 2010)

This presupposition can be predicted in a similar way the presuppositions of change of state verbs above: the truth of the preparatory stage is entailed, and since it is about a time interval that precedes the point of winning, it is not about the event time of winning.

John won the race at $t_{1}$.

a. John participated in the race at $t_{2}$ (where $t_{2}$ is an interval preceding $t_{1}$ ).

Note that $t_{2}$ has to be chosen in such a way that it excludes $t_{1}$, that is $t_{2}$ is over just before $t_{1}$. More precisely, what happens is that there are an infinite number of intervals at which participating is true, and all the sentences that are about intervals that are subintervals of participating that exclude the endpoint are predicted to be presupposed. So suppose John participated in the race from $3 \mathrm{pm}$ to $6 \mathrm{pm}$, and he won it exactly at $6 \mathrm{pm}$. Now all subintervals $\mathrm{t}$ of [3, 6[ (that is the interval that excludes the endpoint $6 \mathrm{pm}$ ) are such that it is true at $t$ that John participated in the race at $\mathrm{t}$. As for all such $\mathrm{t}$, the sentence that John participated at $\mathrm{t}$ is not about $\mathrm{t}_{1}=6$ pm, every proposition expressing that John participated at some subinterval of $[3,6[$ will be predicted to be presupposed. But the conjunction of all these propositions is equivalent to the proposition that John participated during [3, 6[, which is therefore the felt presupposition. (Note that the same reasoning also applies to the phase preceding the change in change of state verbs discussed in the previous section: here too the actual presupposition that arises is the one that is true at the maximal interval at which the preparatory stage holds.) The implication that John also participated at the point of winning the race, in the above example at $6 \mathrm{pm}$, arises as an implicature from the presupposition that he participated during [3, 6[. Indeed John did not win the race because he quit before the end seems to have a different status than John 
did not win the race because he did not participate: the latter feels like a correction or cancellation, while the former is neutral. ${ }^{28}$

Looking beyond the scope of change of state and achievement verbs, it is generally predicted that entailments of atomic sentences that are not about the event time will be presupposed. This prediction seems to be borne out too. An example might be the sentence with the simple transitive predicate kill such as (54). Some plausible lexical entailments might be $\varphi, \psi$, and $\xi$ as shown below.

John killed Bill

a. $\varphi=$ John killed Bill at $\mathrm{t}_{1}$

b. $\psi=$ Bill is dead at $\mathrm{t}_{1}$

c. $\chi=$ Bill was alive at $t_{2}$ (where $t_{2}$ refers to some time before $t_{1}$ )

Among the above, $\chi$ is not about $\mathrm{t}_{1}$ and is therefore predicted to be presupposed. Notice again the contrast between the entailment of (54) that Bill was alive at $t_{2}$ and the inference that Bill continued to be dead after the event time of the killing. While the first is indeed a lexical entailment, the second is only a pragmatic inference that follows from our world knowledge, as shown by the difference in the acceptability of the following pair.

(55) a. \#John killed Bill, but he was never alive before.

b. John killed Bill, but then he resurrected.

Another example might be the case of response-stance predicates. These predicates are usually taken to assert the truth of some proposition $\mathrm{p}$ and presuppose that someone (usually other than the subject, though this might not be necessary) has asserted or proposed that $\mathrm{p}$ is false. An example of such a verb is deny:

(56) John denied that it was raining

a. $\quad \psi=$ John asserted at $\mathrm{t}_{1}$ that it was not raining

b. $\varphi=$ Someone (other than John) asserted at $t_{2}$ that it was raining (where $t_{2}$ is some interval before $t_{1}$ )

Similarly as we have seen in the case of change of state verbs, $\varphi$ is not about the event time $t_{1}$, and is therefore predicted to be presupposed, which seems to be correct.

$\overline{28}$ Mandy Simons (p.c.) has asked about examples such as (i):

(i) a. John is winning the race (at time $t_{1}$ ).

b. John is participating in the race (at time $t_{1}$ ).

One possibility in the present system is that in these cases too, the implication that John is participating at the time of winning is an implicature of the presupposition that is about the time strictly before the winning. Alternatively, perhaps the progressive interacts with presuppositions in non-trivial ways. I will leave answering this question for the future. 


\subsubsection{Cognitive change of state verbs}

Cognitive change of state verbs work on the one hand as regular change of state verbs (presupposing the truth of a previous state), and on the other hand as factive verbs (having a factive presupposition). These presuppositions arise in the same way as with change of state verbs and with factives, respectively, and are therefore straightforwardly predicted by the present analysis. This predicts correctly that (57a) and (57b) will be the presuppositions of (57).

(57) Peter discovered at $t_{1}$ that Mary is tired at $t_{1}$

a. Peter did not know that Mary is tired at $t_{2}\left(\right.$ where $\left.t_{2}<t_{1}\right)$

b. Mary is tired at $t_{1}$

The entailment in (57a) about a previous stage is not about the matrix tense argument $t_{1}$ of (57), for the same reasons as the entailment about a previous stage of change of state verbs was not about the matrix time argument, and is therefore predicted to be presupposed in the same way. The entailment in (57b) is not about the matrix event time just like the veridical entailments of factives, and is predicted to be presupposed for this reason. Thus the two presuppositions of cognitive change of state verbs can be derived exactly as the presuppositions of factives and change of state verbs respectively.

\section{The top-down process: presupposition suspension}

So far we have been concerned with the bottom-up mechanism that predicts the presuppositions of soft triggers. This mechanism took as its input the semantic entailments of a sentence $S$, and flagged one or more of these as presupposed. But as was mentioned in the outset, the output of this process can be modified by contextual factors, which might result in the presuppositions being suspended, or rather, not even generated in the first place. What happens in these cases is that the context warrants a secondary main point, different from the default one. Since presuppositions have to be independent from both the default and the secondary main points, what would be a presupposition by the bottom-up process will not be independent from the main point any more, and hence will not be predicted to be presupposed. This section spells out two such contextual effects, brought about by focus and evidential verbs. This is not meant to be exhaustive, and the possibility that further such processes might be identified in the future should be kept open. But note that such contextual shifts in what presupposition is triggered are assumed to be brought about by linguistic factors within the sentence itself. Thus unlike for Simons et al. (2010), simply changing the background question is not predicted to lead to a shift in presuppositions.

\subsection{Focus}

Famously, it has been argued in the literature that presuppositions of soft triggers can be suspended (also referred to as contextual neutralization (see Abbott 2006) or 
local accommodation in dynamic semantics) in some circumstances. Here is a classic example from Karttunen (1971b):

(58) If I discover/realize later that I have not told the truth, I will confess it to everyone.

The traditional view about examples such as above is that presupposition is suspended because it clashes with an implicature, in the above case the implicature of the conditional that the speaker is ignorant about the truth of the antecedent of the conditional. The most influential accounts in this spirit have been given by Stalnaker (1974), Gazdar (1979), van der Sandt (1992) (cf. also Chierchia and McConnellGinet 2000; Kadmon 2001; Simons 2001; Beaver 2001, 2004; Abbott 2006; Abusch 2010; Klinedinst 2009 and references therein for further discussion). Examples such as (58) contrast with (59), which is hard to understand as non-presuppositional.

If I regret later that I have not told the truth, I will confess it to everyone.

The reason for this, according to some of the above authors, is that in these cases the presupposition of the antecedent clause (that the speaker believes that he has not told the truth) does not clash with the ignorance implicature of the conditional (that it is open whether he will come to regret that he has not told the truth). The difference between examples such as (59) and (58) is also the prime reason why some presuppositional verbs such as regret are often not classified among soft triggers.

It has been suggested however that a more careful look at the data casts doubt on analyzing presupposition suspension as a result of a clash between presuppositions and implicatures. Beaver (2004) in particular cites many naturally occurring examples where suspension occurs with the 3rd person as well, which is not predicted by the cancellation-by-implicature proposals. He also suggests that rather than a clash with implicatures, the determining factor for whether suspension is observed is the informational, focus structure of the sentence (cf. also Kadmon 2001). As Beaver observes, (60b), in which the verb is focused, suggests that the student is guilty. This contrasts with (60a), in which the embedded clause is focused, where there is no such implication ${ }^{29}$ :

(60) a. If the TA discovers that [your work is plagiarized $]_{\mathrm{F}}$, I will be [forced to notify the Dean $]_{\mathrm{F}}$.

b. If the TA [discovers $]_{\mathrm{F}}$ that your work is plagiarized, I will be [forced to notify the Dean $]_{\mathrm{F}}$.

Beaver also notes that focusing the verb in the classic examples such as (59) has the effect that either the presupposition projects, or the sentence is quite odd. Thus he concludes that focusing and information structure plays the crucial part in presup-

29 Example (60a) is slightly modified from the original, the focused part being the entire embedded clause in the present discussion, but only the verb plagiarized in the original version. These two cases are hard to tell apart phonetically in English, but Hungarian indicates that more likely the latter is the case. 
position suspension, rather than a clash with implicatures. Convinced by Beaver's (2004) arguments, in this paper I also assume that the cases of presupposition suspension follow from focus. The remainder of this section attempts to explain how the paradigm illustrated in (60) might arise. I also provide evidence that suspension due to focus can affect alleged hard triggers such as regret as well. This I take to suggest that all verbal triggers belong to the soft-presuppositional category.

Focus is usually taken to be the part of a sentence that conveys the new or highlighted information, thus the information that directly answers a background question. In this sense, focus grammatically signals the presence of a background question. What I will assume here is that grammatically marked background questions can introduce a secondary (or pragmatic) main point. Secondary main points concern the event time of the sentence expressing the most direct proposition that answers the background question. The presupposition triggering mechanism looks both at the default (grammatical) and the secondary (pragmatic) main points and requires the presupposition to be independent from both of these. This derives the above data in the present framework. Let's look at the above example in more detail, zooming in on the antecedent of the conditional. (As mentioned in the outset, I assume that presuppositions are generated at the embedded level, and are then subject to projection rules.)

(61) a. The TA discovers $\left(\right.$ at $\left.t_{1}\right)$ that [your work is plagiarized $\left(\right.$ at $\left.\left.t_{2}\right)\right]_{F}$.

b. The TA [discovers $]_{\mathrm{F}}\left(\right.$ at $\left.\mathrm{t}_{1}\right)$ that your work is plagiarized $\left(a \mathrm{t}_{2}\right)$.

Assume that $t_{1}$ and $t_{2}$ are interpreted as picking out non-overlapping intervals. ${ }^{30}$ In (61a), focusing the embedded clause indicates that the background question is What will the TA discover? The direct answer to this question is a proposition, namely the proposition denoted by the embedded clause that your work is plagiarized at $t_{2}$. Since the secondary main point is the information that is about the matrix tense argument of the sentence expressing the direct answer to the background question, in this case the secondary, pragmatic main point concerns the information that is about $t_{2}$. So what has to be checked is whether the information conveyed by the embedded clause is about $t_{2}$. The answer is yes: changing the properties of the world at $\mathrm{t}_{1}$ will influence the truth of $\psi=$ your work is plagiarized at $\mathrm{t}_{2}$. There are two models $\mathbf{M}, \mathbf{M}^{\prime} \in \mathrm{Mt}^{2}$ such that $\mathbf{M} \models \psi$ and $\mathbf{M}^{\prime} \not \psi \psi$ : simply take a model $\mathbf{M}$ st. $\mathrm{M} \models \psi$, form a $\mathrm{t}_{2}$ variant $M^{\prime}$ in which your work is not plagiarized at $\mathrm{t}_{2}$ : it follows that $\mathbf{M}^{\prime} \not \forall \psi$. Since $\psi$ is not independent from the secondary main point (as it is about it), it is not predicted to be presupposed.

The situation is different in (61b). Here the focus on the matrix verb indicates that the background question is What will the TA do? The direct answer to this question is a proposition that restates the main clause of the antecedent of the conditional and therefore the pragmatic main point of the sentence concerns the

\footnotetext{
30 Admittedly this might be not very realistic in the case of a stative complement as be plagiarized, but is harmless and so I will stick to it for the sake of simplicity. The reason why it is a harmless assumption is that because of the non-accidental criterion in the presupposition triggering mechanism we could always just look at a $\mathrm{T}$-alternative for which $\mathrm{t}_{1}$ and $\mathrm{t}_{2}$ pick out non-overlapping intervals more realistically: The TA discovers that your work was plagiarized.
} 
main clause and the matrix tense. Since this is the same as the default (grammatical) main point, we derive the same presupposition as in the default, unfocused case: the truth of the embedded complement is independent from the main point (i.e. it is not about the matrix tense argument) and is therefore presupposed.

In Hungarian, a language which marks focus syntactically, the pattern identified by Beaver can be replicated more generally, even with verbs such as tud 'know' and alleged hard triggers such as regret. In Hungarian most verbs that take propositional complements, can have a pronominal argument in the main clause (in this case azt 'that.acc') that is anaphoric to the embedded proposition. This pronoun can be focused: when it is, as in (62a), the truth of the complement is not presupposed any more. This is in contrast to (62b), in which instead of the propositional anaphor the verb is focused: here factivity is preserved: doubt.1sg that Peter that.acc knows that falls the rain 'I doubt that what Peter knows is that it is raining.'
a. Kétlem, hogy Péter $[\mathrm{azt}]_{\mathrm{F}}$ tudja, hogy esik az eső.
b. Kétlem, hogy Péter [tudja $]_{\mathrm{F}}$ (azt), hogy esik az eső. doubt.1sg that Peter knows (that.acc) that falls the rain 'I doubt that Peter $[\text { knows }]_{\mathrm{F}}$ that it is raining.'

The example above can be predicted in the same way as the previous English data. Further, examples analogous to (59) with regret also show sensitivity to focus. The sentence (63a), in which the pronoun that is anaphoric to the embedded clause in the antecedent is focused, is a coherent statement, which shows that the presupposition here can be suspended. However (63b), in which the verb itself is focused, is odd because it feels contradictory.

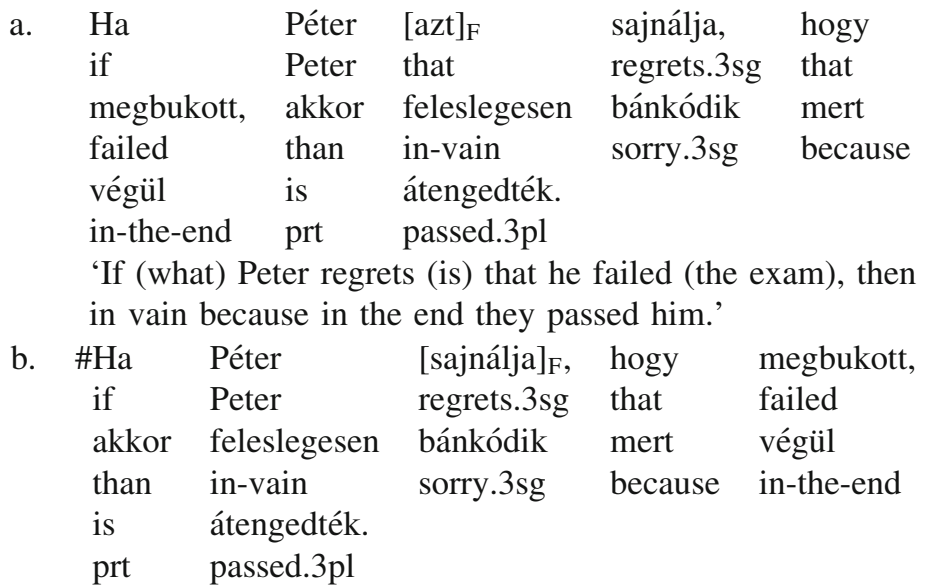

'If Peter regrets that he failed (the exam), then he is sorry in vain because in the end they passed him.'

Thus the present account is able to derive why in certain contexts the presuppositions of soft triggers disappear: in these cases focus indicates the presence of a 
background question and a secondary main point that is different from the default main point. Since the presupposition has to be independent from this secondary main point as well, presuppositions are simply not generated. ${ }^{31}$

Note that the cases discussed above are different from those in which the presupposition is globally accommodated (cf. Karttunen 1974; Thomason 1990, among others): in these (unembedded) cases the content of the presupposition is implied, but it fails to be pragmatically presupposed:

(64) We regret to inform you that the swimming pool is closed. (Thomason 1990)

Arguably, such examples show a more general property of conversation that speakers can silently adjust their context to accommodate presupposed information (cf. Stalnaker 1974, 2002; Karttunen 1974; Lewis 1979; Heim 1983; van der Sandt 1992; von Fintel 2008, among others). Therefore examples such as (64) can be assumed to be presuppositional as usual. Such examples thus do not show the "softness" of soft presuppositions, but show that the common ground assumed by conversational participants is influenced by utterances in rather subtle ways. In contrast, the cases of suspension discussed above require flexibility in predicting what is actually implied by a sentence/what presupposition gets projected, not silent contextual adjustments.

\subsection{Parenthetical uses of verbs}

Simons (2007) (partly following Hooper 1975) observes that certain clause embedding verbs such as hear, see, believe, discover, know, etc. have semantically parenthetical uses. In these cases the embedded clause carries the main point of the utterance, while the matrix clause serves an evidential function of identifying information source, emotional attitude, etc. An example is the conversation below:

A: Why didn't Louise come to the meeting yesterday?

B: I heard that she's out of town.

Some of the verbs that admit such parenthetical uses are members of the class commonly thought of as factive verbs (e.g. see, know, discover, etc.). Simons notes that when used in this parenthetical manner, these verbs loose their presuppositionality: In the examples below the information that Luise is out of town is

\footnotetext{
31 Another case of presupposition-suspension based on focus might be the example in (i), in which the question an be understood in a non-presuppositional case. In Hungarian, the example only works if the adverb recently is present, and is in focus position. Without the adverb, the question is still presuppositional.
}

(i) I notice you are chewing on your pencil. Have you recently stopped smoking? (Geurts 1994)

Possibly, what is happening here is that the adverb makes the entire stretch of time signaled by recently the main point of the utterance. This allows a non-presuppositional understanding of the question, if the time of smoking falls within the stretch of time designated by the adverb. 
presented as new information, and not as information that is already entailed by the common ground or presupposed. Some illustrative examples from Simons' paper:

(66) A: Why isn't Louise coming to our meetings these days?

B: Henry discovered/realized/figured out/learned that she's left town.

Yikes! I just remembered/realized that I didn't turn off the stove!

Note that in this case global accommodation is not really an option, because of the explicit question of A. As regards projection facts, it also seems that the above verbs can act in a way as if their complement was not presupposed. With factives such as know, such facts are harder to find but not impossible (cf. also (42) above). Simon's example with know:

(68) Context: We are in a restaurant, and you notice that I keep staring at a diner at another table. Finally I say:

I KNOW I've run into that guy somewhere, but I can't for the life of me think where it was.

According to Simons, "In the context, an utterance of [(68)] might well be more natural than utterance of the same sentence without I know. However, I know doesn't seem to add to the communicated content. Rather, by prefacing the (main point) claim with $I K N O W \ldots$, the speaker makes explicit her strong commitment to the truth of that claim. The emphatic stress may serve to bring out the implicit contrast with weaker degrees of commitment."

Simons proposes that in the above cases the main verb is used in an evidential way. Evidentials are words or morphemes that express the source of information or the type of evidence that the speaker has for the information being conveyed. In many languages of the world these markers of information are highly grammaticalized, and might even be obligatory. (cf. Speas 2008; Aikhenvald 2006). The most common information types expressed are direct information (which might e.g. be visual, auditory, other sensory, etc.) and indirect information (e.g. reported, inferred, etc.), with variation among languages of how the evidence types are divided. Most often, evidentials are analyzed as either illocutionary operators (cf. Faller 2002; Davis et al. 2007, etc.) or as modal operators (cf. Garrett 2000; Izvorski 1997, etc.), with languages possibly differing in the semantic properties of their evidentials. Another source of theoretical (and perhaps empirical) variation is whether the content of evidential markers becomes part of the propositional content. Further, given that evidentials either serve an illocutionary or a modal function, the content modified by the evidential is (also) the main point of the utterance. This can also be seen with the evidential verbs surveyed above, as was pointed out by Simons, many of which allow a so-called slifting construction. In such cases the main verb is inserted as a parenthetical comment into the subordinated clause, as in (69):

John, I heard, is out of town. 
Simons' (2007) idea has interesting consequences for the present proposal. In cases where the matrix verb is used in an evidential way, there might also be a second (pragmatic) main point besides the grammatically defined default one, which is derived contextually. The second main point concerns the clause "modified" by the evidential, the syntactically embedded clause. Technically the secondary main point is the information that is about the time of the syntactically embedded verb. Let's repeat B's response in (65) here:

I heard $\left(a t_{1}\right)$ that she's out of town (at $\left.t_{2}\right)$

Assume that $t_{1}$ and $t_{2}$ are assigned different time intervals. The secondary main point is the information that is about the matrix time of the clause modified by the evidential, in this case $t_{2}$. The sentence $\psi=$ that she is out of town at $t_{2}$ is about $t_{2}$, since changing the properties of the world at $t_{2}$ could influence its truth. More precisely, there are two models $\mathbf{M}, \mathbf{M}^{\prime} \in \mathbf{M}^{t 2}$ such that $\mathbf{M} \models \psi$ and $\mathbf{M}^{\prime} \not \models \psi$ : simply take a model $\mathrm{M}$ st. $\mathbf{M} \models \psi$, form a $\mathrm{t}_{2}$ variant $\mathbf{M}^{\prime}$ in which Louise is not out of town at $\mathrm{t}_{2}$ : it follows that $\mathbf{M}^{\prime} \not \forall \psi$. Thus since $\psi$ is not independent from the secondary main point (as it is about it), it is not predicted to be presupposed.

\section{Adding presuppositions contextually}

The previous section looked at cases where semantic presuppositions were suspended. However, presuppositions sometimes can also be contextually added to otherwise non-presuppositional expressions (cf. Simons 2001; Schlenker 2010). This happens in certain situations where a contextual entailment is made salient: it is this contextual entailment that acts as if it was presupposed. Thus there seem to be cases where presuppositions arise not from semantic entailments, but from contextual or commonsense entailments. This section looks at such cases. It is proposed that these can be predicted by the present mechanism as well: all we need to do is to allow the triggering mechanism to operate on a contextually enriched set of entailments.

Certain normally non-presuppositional expressions, as was noticed by Schlenker (2008, 2010), might nevertheless behave as if they were presuppositional in some contexts. Schlenker calls such expressions 'part-time triggers'. An example is the verb announce. In some contexts, it does not entail the truth of its complement and in these contexts it does not presuppose the truth of its complement either. In other contexts, it entails and presupposes the truth of its complement. Such cases, he argues, point towards a triggering theory that predicts presuppositions not only based on the meaning of the expressions involved, but based on the literal meaning of the expressions together with the linguistic and extra-linguistic context in which these expressions appear. Let's look at an example:

(71) Mary has announced that she is pregnant

a. Scenario 1: Mary is 30 years old and she is expected to be reliable. Therefore the context entails the truth of the embedded proposition.

$\rightarrow$ (71) presupposes that Mary is pregnant 
b. Scenario 2: Mary is 7 years old and is not expected to be reliable.

Therefore the context does not entail the truth of the embedded proposition. $\rightarrow$ (71) does not presuppose that Mary is pregnant

As Schlenker points out, the verb announce contrasts minimally with the verb inform, which seems to lexically entail and presuppose the truth of its complement in the above context.

The mechanism proposed in this paper can be extended to handle the above facts. What is needed is to allow contextual entailments to enter the pool of candidate entailments for presuppositions. Then if the embedded proposition is contextually entailed, it is also be predicted to be presupposed. Otherwise it isn't. Thus (71a) is predicted to presuppose its complement, but not (71b). So far this is simply an extension of the above mechanism to include contextual entailments.

Interestingly, there are further cases, discussed in Schlenker (2006), which show that inform itself is a part time trigger. In contexts in which the truth of the complement is in question and the subject is assumed to be a very reliable source of information regarding the truth of the complement, the factive inference of both announce and inform disappears. Look at the context below:

(72) George is the family butler. He is very reliable. If he says p, then we can infer that $\mathrm{p}$ is the case, and if he does not say $\mathrm{p}$, we can infer that $\mathrm{p}$ is not the case.

Has George announced/informed the guests that dinner is ready?

$\rightarrow$ there is no implication that dinner is ready.

This example connects back to the cases of evidential verbs: a plausible thing to say about it is that the butler being a completely reliable source for the information in question (whether dinner is ready), the embedded clause becomes the pragmatic main point. In effect, the question is interpreted as 'Is dinner ready (according to the most reliable source)?' This makes the truth of the embedded clause not independent from the secondary main point (indeed it is equivalent to it) and therefore the truth of the embedded clause is not predicted to be presupposed, despite being entailed.

\section{Discussion}

This paper proposed that presuppositions of soft triggers can be predicted from assumptions about the attentional status of the information expressed by the sentence in which they occur: information that we do not pay attention, by default or in a context is presupposed. The triggering mechanism looked at atomic sentences. Presuppositions of complex sentences are assumed to be derived by applying a separate projection mechanism. This means that different sets of rules determine how presuppositions are generated, and how they are transmitted.

The proposal is context sensitive in two ways: First, as was discussed in Sect. 5, certain grammatical markers such as evidentials or focus might indicate the 
presence of secondary (pragmatic) main points, which can have the effect of suspending certain presuppositions. Second, as shown in Sect. 6, certain presuppositions might be derived based on contextual entailments, as was the case of part-time triggers.

Finally, it should be noted that the mechanism is not exhaustive: it does not exclude that other mechanisms might turn entailments not predicted to be presuppositions by the current account into presuppositions. This is presumably the case with all the presuppositions that are not in the scope of this proposal, that is any presupposition other than the presuppositions of soft triggers (verbs). ${ }^{32}$

\subsection{Some predictions}

In general the theory makes the prediction that (at least in neutral contexts where secondary main points are not evoked) verbs that entail the truth of their propositional complement will also presuppose the truth of this complement, unless it is lexically specified by the matrix verb that tense argument of the embedded complement has to be co-indexed with the matrix tense. This is because, if the tenses are in principle independent, there will always be a T-alternative such that the proposition corresponding to the proposition denoted by the complement is not about the event time of the matrix clause of the T-alternative. The difference in presuppositionality between a factive verb such as know and a non-factive one such as believe follows from the fact that the latter do not entail that their complement is true, i.e. their veridicality. ${ }^{33}$

Further, the system makes the prediction that any entailment whose sentential description does not contain a matrix tense argument or a quantified tense argument is presupposed. Conversely, entailments of a sentence $S$ whose linguistic form contains the matrix tense argument of the sentence and is not tautologous is not predicted to be presupposed (at least not by the present mechanism). Therefore it is predicted that presuppositions of change of state or achievement verbs will be about some time other than the event time of the verb. As far as I know this prediction is borne out. It is also predicted that entailments of change of state verbs that are not about the event time cannot be not presupposed. Recall that the inference we might get from stop that the final state continues to hold is not itself an entailment, unlike the inference that the previous state held for some time before the event time, as it

32 Some cases of alleged verbal presuppositions might belong to the case of existential presuppositions as well. One such case might be the verb accompany, which has been argued in Abusch (2010) to be presuppositional: In particular (i) is claimed to presuppose that Mary went to the airport.

(i) John accompanied Mary to the airport

presupposition: Mary went to the airport

But it seems that this presupposition arises from a syntactically more complex sentence, namely John accompanied Mary, who was going to the airport. Since in this case we have a relative clause, the inference we observe might also be an existential presupposition.

33 It has been often noted that factive verbs are also veridical, cf. Karttunen (1971b), Giannakidou (1998, 1999), among others. But the present paper goes beyond this claim, in trying to explain why veridicality leads to presuppositionality. 
was shown in (48). The theory also makes the prediction that if two aspectual verbs were to differ only in the lengths of the interval denoted by the event time, their corresponding presuppositions should also differ. This prediction seems to be borne out as well, as was shown by the Hungarian examples in (50)-(51).

\subsection{Challenges? Fillmore (1971) and Abusch (2002, 2010)}

Since presuppositions are predicted from meanings of sentences, the proposal also makes the prediction that atomic sentences that have the same meaning should trigger the same presuppositions. This seems largely correct. However, some cases have been offered in the literature that might seem to challenge this prediction. Fillmore (1971) has argued that there was a near-symmetry between the predicates accuse-criticize, in that ' $\mathrm{a}$ accused $\mathrm{b}$ of p' presupposed that $a$ judged the action denoted by $p$ bad, and asserted that $b$ did $p$, 'a criticized $\mathrm{b}$ for $\mathrm{p}$ ' presupposed that $b$ did $p$ and asserted that $a$ indicated that $p$ was bad. On closer observation though this near-symmetry turns out to be imprecise. First, it is not true that both predicates contribute the meaning that $a$ judges/indicates that $p$ is bad. While this might be approximately correct for criticize, accuse seems to contribute a stronger meaning suggesting that $p$ is reproachable in general, as can be seen from the examples below.

(73) a. John criticized Mary for cleaning the bathroom.

b. John accused Mary of cleaning the bathroom.

Further, while criticize seems to entail and presuppose the truth of the embedded complement, accuse does not seem to entail the truth of the embedded complement, only that the subject asserted it. Interestingly, given these refinements the present proposal actually predicts the correct presupposition facts for the above pair: accuse triggers the sortal presupposition that $p$ is reproachable, but does not in fact entail the truth of its complement, while criticize entails and presupposes the truth of its complement, but does not entail that $p$ is morally reproachable, only that the subject finds it undesirable.

A more serious candidate for a pair where the same overall meaning might cooccur with different presuppositions was put forth by Abusch $(2002,2010)$. She has argued that the pairs be right-be aware are symmetric in the following way:

\footnotetext{
a. John is right that dinner is ready

asserts: Dinner is ready

presupposes: John believes that dinner is ready

b. John is aware that dinner is ready

asserts: John believes that dinner is ready

presupposes: Dinner is ready
}

However, as argued in Schlenker $(2008,2010)$ it seems that syntactically the two do not behave alike, and that (74a) is syntactically more complex, akin to (75):

John is right in claiming that dinner is ready 
As Schlenker convincingly shows, the syntactic and semantic difference among the two predicates seems to be supported by various syntactic diagnostics such as weak crossover facts. This is a step towards distinguishing the two predicates, yet it does not fully grant the right predictions for the present proposal. While it is correctly predicted that be aware should presuppose $\psi$ in (76), the sentence with is right is predicted to presuppose both $\varphi$ and $\psi$, but it only presupposes $\varphi$.
(76) a. $\varphi=$ John claimed that dinner was ready (at some time $t_{2}$ before the event time)
b. $\quad \psi=$ Dinner is ready

One possibility for why the predicted presupposition $\psi$ is not manifest is that it is canceled as in most embedded contexts it would be incompatible with the assertion or some implicature of the assertion. Thus (77a) asserts that John made an incorrect claim, while $(77 \mathrm{~b}, \mathrm{c})$ imply that the speaker does not know whether John's claim is correct. Each of these cases is incompatible with the presupposition that dinner is ready.

a. John is not right that dinner is ready

b. Is John right that dinner is ready?

c. If John is right that dinner is ready, we should proceed to the dining hall.

Symmetric pairs, if real, would pose a challenge to any theory that attempts to derive presupposition triggering on the basis of the meaning of $S$ alone. If the arguments in this paper and Schlenker (2010) are on the right track, to date no really convincing case has been found among verbal triggers. ${ }^{34}$

\section{Conclusion}

This paper proposed that presuppositions of soft triggers arise from the way our attention structures the informational content of a sentence. Some aspects of the information conveyed are such that we pay attention to them by default, even in the absence of contextual information. On the other hand, contextual cues or conversational goals can divert attention to types of information that we would not pay attention to by default. Either way, whatever we do not pay attention to, be it by default, or in context, is what ends up presupposed by soft triggers. The paper attempted to predict what information in the sentence is likely to end up being the main point (i.e. what we pay attention to) and what information is independent from this, and therefore likely presupposed. It was proposed that this can be calculated by making reference to event times. The notion of aboutness used to calculate independence is based on that of Demolombe and Fariñas del Cerro (2000).

34 C. Potts (p.c.) pointed out that two vs. both and more than once/twice vs. again might be further examples of (near-)synonymous pairs that differ only in their presuppositions. As the present paper is only concerned with soft presupposition triggers, I leave them aside here. 
The proposed mechanism was context sensitive, with two main sources of context sensitivity. First, I assumed that the main point can be shifted in certain cases by focus or evidential expressions. This predicts the examples of presupposition suspension. Second, the pool of candidates for presuppositions might include contextual entailments as well as semantic entailments. This predicts that some expressions that are not necessarily presuppositional might trigger presuppositions in certain contexts. Finally, the proposed mechanism also made a number of predictions about the type and form of the presuppositions of soft triggers.

Acknowledgements Many thanks to the anonymous reviewers and to Chris Potts for helpful comments and suggestions on this paper. Thanks also to Denis Bonnay, Nathan Klinedinst, Daniel Rothschild and Philippe Schlenker for many conversations on various previous versions, Emmanuel Chemla, Paul Egré, Giorgio Magri, David Nicolas and Tim Williamson for comments on a previous draft and Edgar Onea, Benjamin Spector, Pascal Amsili, Paula Menéndez-Benito, David Beaver, Mandy Simons, Craige Roberts, Sigrid Beck, Robert Demolombe, Nicholas Asher, Paolo Santorio, Kyle Rawlins, Jacopo Romoli, François Recanati, Chris Barker, Danny Fox, Eytan Zweig, Ofra Magidor, Anna Szabolcsi, Bridget Copley, Matthew Towers and the audiences at LoLa10, The Aboutness Workshop in Toulouse, JSM10, University of York, University of Tübingen, University of Göttingen, SALT20, the Riga Symposium on Semantics, IJN and IRIT for very helpful comments and questions at various stages of this research. All remaining errors are my own. This research was supported by the ESF (Euryi grant to P. Schlenker), The Mellon Foundation and the Lichtenberg Kolleg, Georg-August Universität Göttingen.

Open Access This article is distributed under the terms of the Creative Commons Attribution License which permits any use, distribution, and reproduction in any medium, provided the original author(s) and the source are credited.

\section{References}

Abbott, B. (2000). Presuppositions as nonassertions. Journal of Pragmatics, 32(10), 1419-1437.

Abbott, B. (2006). Where have some of the presuppositions gone? In B. J. Birner \& G. Ward (Eds.), Drawing the boundaries of meaning: Neo-Gricean studies in pragmatics and semantics in honor of Laurence R. Horn (pp. 1-20). Philadelphia: John Benjamins.

Abrusán, M. (2011). Triggering verbal presuppositions. In N. Li \& D. Lutz (Eds.), Semantics and linguistic theory (SALT) 20 (pp. 684-701) (eLanguage).

Abusch, D. (2002). Lexical alternatives as a source of pragmatic presuppositions. In B. Jackson (Ed.), Proceedings of SALT 12, 2002. Cornell University, CLC Publications.

Abusch, D. (2010). Presupposition triggering from alternatives. Journal of Semantics, 27(1), 37-80.

Aikhenvald, A. (2006). Evidentiality. Oxford: Oxford University Press.

Beaver, D. I. (2001). Presupposition and assertion in dynamic semantics. Stanford: CSLI Publications.

Beaver, D. I. (2004). Have you noticed that your belly button lint colour is related to the colour of your clothing? In R. Bauerle, U. Reyle, \& T. E. Zimmerman (Eds.), Presupposition: Papers in Honor of Hans Kamp. Emerald Group Publishing Limited.

Chemla, E. (2009). Similarity: Towards a unified account of scalar implicatures, free choice permission and presupposition projection. Under revision for Semantics and Pragmatics.

Chemla, E., \& Bott, L. (2011). Processing presuppositions: Dynamic semantics vs pragmatic enrichment. Language and Cognitive Processes (to appear).

Chierchia, G., \& McConnell-Ginet, S. (2000). Meaning and grammar: An introduction to semantics. Cambridge, MA: MIT Press.

Davis, C., Potts, C., \& Speas, M. (2007). The pragmatic values of evidential sentences. In M. Gibson \& T. Friedman (Eds.), Proceedings of Semantics and Linguistic Theory 17 (pp. 71-88). Ithaca, NY: CLC Publications.

Demolombe, R., \& Fariñas del Cerro, L. (2000). Towards a logical characterization of sentences of the kind "sentence $\mathrm{p}$ is about object c". In S. Holdobler (Ed.), Intellectics and computational logic: Papers in honor of Wolfgang Bibel. Dordrecht: Kluwer. 
Demolombe, R., \& Fariñas del Cerro, L. (2010). Information about a given entity: From semantics towards automated deduction. Journal of Logic and Computation, 20(6), 1231-1250.

Egré, P. (2008). Question-embedding and factivity. In F. Lihoreau (Ed.), Grazer Philosophische Studien 77 (pp. 85-125). Rodopi.

Faller, M. (2002). Semantics and pragmatics of evidentials in Cuzco Quechua. Ph.D. thesis, Stanford University.

Fillmore, C. (1971). Types of lexical information. In D. Steinberg \& L. Jakobovits (Eds.), Semantics. An interdisciplinary reader in philosophy, linguistics and psychology (pp. 370-392). Cambridge: Cambridge University Press.

Garrett, E. J. (2000). Evidentiality and assertion in Tibetan. Ph.D. thesis, University of California, Los Angeles.

Gazdar, G. (1979). Pragmatics: Implicature, presupposition and logical form. New York: Academic Press.

Geurts, B. (1994). Presupposing. Ph.D. thesis, University of Osnabrück.

Geurts, B., \& van der Sandt, R. (2004). Interpreting focus. Theoretical Linguistics, 30(1), 1-44.

Giannakidou, A. (1998). Polarity sensitivity as (non) veridical dependency. Amsterdam: John Benjamins.

Giannakidou, A. (1999). Affective dependencies. Linguistics and Philosophy, 22(4), 367-421.

Giannakidou, A. (2009). The dependency of the subjunctive revisited: Temporal semantics and polarity. Lingua, 119(12), 1883-1908.

Ginzburg, J., \& Kolliakou, D. (1997). Events and facts: A semantics of pou and oti clauses. In Greek linguistics (pp. 459-470). Graz: N. Neugebauer Verlag.

Goldstein, E. (2009). Sensation and perception. Belmont, CA: Wadsworth Publishing Co.

Hamblin, C. (1973). Questions in Montague English. Foundations of Language, 10, 41-53.

Heim, I. (1983). On the projection problem for presuppositions. In Proceedings of WCCFL 2 (pp. 114-125).

Hooper, J. B. (1975). On assertive predicates. In J. P. Kimball (Ed.), Syntax and semantics (pp. 91-124). New York \& San Francisco \& London: Academic Press.

Itti, L., \& Koch, C. (2001). Computational modeling of visual attention. Nature Reviews Neuroscience, 2(3), 194-203.

Izvorski, R. (1997). The present perfect as an epistemic modal. In Proceedings of SALT (Vol. 7, pp. 222-239). Cornell: CLC Publications.

Kadmon, N. (2001). Formal pragmatics: Semantics, pragmatics, presupposition, and focus. Oxford: Blackwell.

Karttunen, L. (1971a). Implicative verbs. Language, 47(2), 340-358.

Karttunen, L. (1971b). Some observations on factivity. Papers in Linguistics, 5, 55-69.

Karttunen, L. (1974). Presuppositions and linguistic context. Theoretical Linguistics, 1, 181-194.

Karttunen, L. (1977). Syntax and semantics of questions. Linguistics and Philosophy, 1(1), 3-44.

Karttunen, L., \& Peters, S. (1979). Conventional implicature. In C.-K. Oh \& D. A. Dinneen (Eds.), Syntax and semantics, volume 11: Presupposition (pp. 1-56). New York: Academic Press.

Keshet, E. (2008). Infinitival complements. In A. Gronn (Ed.), Proceedings of Sinn und Bedeutung 12.

Kiparsky, P., \& Kiparsky, C. (1970). Fact. In M. Bierwisch \& K. Heidolph (Eds.), Progress in linguistics (pp. 143-173). The Hague: Mouton.

Klein, E. (1975). Two sorts of factive predicate. Pragmatics Microfiche it 1.1. frames B5-C14.

Klinedinst, N. (2009). Totally hardcore semantic presuppositions. Ms, UCL.

Kratzer, A. (1989). An investigation of the lumps of thought. Linguistics and Philosophy, 12(5), 607-653.

Kusumoto, K. (2005). On the quantification over times in natural language. Natural Language Semantics, 13(4), 317-357.

Landman, F. (1991). Structures for semantics. Dordrecht: Springer.

Lewis, D. (1979). Scorekeeping in a language game. Journal of Philosophical Logic, 8(1), 339-359.

Navalpakkam, V., \& Itti, L. (2005). Modeling the influence of task on attention. Vision Research, 45(2), 205-231.

Partee, B. H. (1973). Some structural analogies between tenses and pronouns in English. The Journal of Philosophy, 70(18), 601-609.

Potts, C. (2005). The logic of conventional implicatures. Oxford studies in theoretical linguistics. Oxford: Oxford University Press.

Quer, J. (2001). Interpreting mood. Probus, 13(1), 81-111.

Romoli, J. (2011). The presuppositions of soft triggers are not presuppositions. In N. Ashton,

A. Chereches \& D. Lut (Eds.), Proceedings of semantics and linguistic theory (SALT) 21.

Rooth, M. (1992). A theory of focus interpretation. Natural Language Semantics, 1(1), 75-116.

Roussou, A. (2010). Selecting complementizers. Lingua, 120(3), 582-603. 
Schlenker, P. (2003). The lazy Frenchman's approach to the Subjunctive. In Proceedings of Romance languages and linguistic theory (pp. 269-309).

Schlenker, P. (2006). Presupposed entailments: The triggering problem revisited. Talk presented at Sinn und Bedeutung 11.

Schlenker, P. (2008). Be articulate: A pragmatic theory of presupposition projection. Theoretical Linguistics, 34(3), 157-212.

Schlenker, P. (2010). Local contexts and local meanings. Philosophical Studies, 151, 115-142.

Simons, M. (2001). On the conversational basis of some presuppositions. In R. Hastings, B. Jackson, \& S. Zvolenszky (Eds.), Semantics and Linguistic Theory, 11. Ithaca, NY: CLC Publications.

Simons, M. (2007). Observations on embedding verbs, evidentiality, and presupposition. Lingua, 117(6), 1034-1056.

Simons, M., Tonhauser, J., Beaver, D., \& Roberts, C. (2010). What projects and why. In N. Li \& D. Lutz (Eds.), Proceedings of semantics and linguistic theory 20 (pp. 309-327). Ithaca, NY: CLC Publications.

Soames, S. (1989). Presupposition. In D. Gabbay \& F. Guenther (Eds.), Handbook of philosophical logic (Vol. IV, pp. 553-616). Dordrecht: Reidel.

Speas, P. (2008). On the syntax and semantics of evidentials. Language and Linguistics Compass, 2(5), 940-965.

Stalnaker, R. C. (1974). Pragmatic presuppositions. In Semantics and philosophy (pp. 197-214). New York: New York University.

Stalnaker, R. C. (2002). Common ground. Linguistics and Philosophy, 25(5), 701-721.

Thomason, R. (1990). Accommodation, meaning, and implicature: Interdisciplinary foundations for pragmatics. In P. Cohen, J. Morgan, \& M. Pollack (Eds.), Intentions in communication (pp. 326363). Cambridge, MA: MIT Press.

van der Sandt, R. A. (1992). Presupposition projection as anaphora resolution. Journal of Semantics, 9(4), 333-377.

Varlokosta, S. (1994). Issues in modern Greek sentential complementation. PhD dissertation. University of Maryland, College Park.

von Fintel, K. (2008). What is presupposition accommodation, again? Philosophical Perspectives, 22(1), 137-170.

Williamson, T. (2002). Knowledge and its limits. Oxford: Oxford University Press.

Wilson, D., \& Sperber, D. (1979). Ordered entailments: An alternative to presuppositional theories. In Syntax and semantics XI: Presupposition (pp. 299-323). New York: Academic Press.

Yablo, S. (2008). Semantic arithmetic. http://www.mit.edu/ yablo/semanticarithmetic.pdf. Accessed 24 April 2012. 